JOINT TRANSPORTATION RESEARCH PROGRAM

FHWA/IN/JTRP-2010/28

Final Report

EXPERIMENTAL EVALUATION AND IMPLEMENTATION OF POST-TENSIONING IN CONCRETE BRIDGE DECKS

\author{
J.A. Ramirez \\ G. Aguilar
}

November 2010 


\section{TECHNICAL Summary}

Technology Transfer and Project Implementation Information

\section{Experimental Evaluation and Implementation of Post-Tensioning in Concrete Bridge Decks}

\section{Introduction}

The primary bridge maintenance problem in Indiana has been identified as the damage to concrete decks either due to corrosion of reinforcement or freezethaw cycles. The use of epoxy-coated reinforcement and a minimum thickness of concrete cover have been the primary system for protection against corrosion for the last several decades. However, when the integrity of the epoxy coating is compromised, the initiation of corrosion depends on the chloride concentration at the level of reinforcement. This chloride concentration is directly related to the cracking in the bridge deck. Therefore, the control of deck cracking becomes of paramount importance.

A simple and ingenuous solution to control the cracking of concrete bridge decks, effectively improving their durability, was suggested by Tedesko (1976) and Blaha (1980) through the use of prestressing. Poston et al. (1987) observed that the use of transverse prestressing resulted in controlling the extent of cracking and thus preventing the penetration of chloride ions to the reinforcement level. The main benefit observed by Poston et al. for a transversally prestressed bridge deck was the elimination and control of cracking, which restrict the penetration of all water, chloride and oxygen, thus extending the life of the bridge.

In JTRP Project FHWA/IN/JTRP-2002/26, SPR2409 (Ramirez and Smith-Pardo, 2002), design expressions for the use of transverse post-tensioning were developed based on extensive analytical studies. Experimental results from previous research programs -particularly that of Poston et al. (1987)- were used to validate the design specifications. The design specifications developed in the Ramirez and Smith-Pardo (2002) report were preliminary and not proposed for immediate use until:

1. The key modeling assumptions in the parametric study were tested in the laboratory, and

2. A field-phase consisting of the monitoring of a pilot structure was implemented.

The research program described in this report addresses the first recommendation of Ramirez and Smith-Pardo (2002). The main objective of this research project is to evaluate in the laboratory the key modeling assumptions of the analytical study conducted by Ramirez and Smith-Pardo (2002) and their recommendations on distribution of stress in concrete bridge decks resulting from transverse post-tensioning. The experimental program documented in this report was put together and conducted to achieve the previously stated objective. A rectangular concrete bridge deck supported on precast prestressed concrete girders was built and 32 tests were conducted with it. The key parameters of the study were the effect of both girder boundary conditions and position of the diaphragms. The number of steel diaphragms was varied from five to none, and the applied transverse stress from 400 to 1200 psi. Also, the restrain force at one of the support lines was varied to evaluate the effect of end-restraint on the distribution of transverse post-tensioning. Due to laboratory limitations, the effect of the angle of skew of the deck was not evaluated. 


\section{Findings}

The experimental results showed that the steel diaphragms participated during the application of transverse post-tensioning to the deck. The measurements indicated that when present regardless of the number and location, the diaphragms were subjected to axial compression, even though this was small in magnitude.

The similarities between plots in Figure 4.3 and Figure 4.5 showed that the effect of endrestraint at the East support line (right side of the plots) on the distribution of transverse strains along the bridge deck was very limited. At the West end (left side of the plots), there was a concentration of strain throughout all 32 tests. This observation could be explained by a reduction in stiffness from damage to the deck during the vertical post-tensioning operation. However, Figures 4.3 and 4.5 showed that the distribution of strains remained essentially the same in shape and magnitude after removal of the end restraint.

The calculated stresses in the concrete using strain measurements on the transverse deck reinforcement using linear elastic behavior and actual measured concrete properties showed agreement with the values calculated from the strain measurement on the transverse posttensioning bars. This observation is limited to the range of post-tensioning force used in these tests. However, this agreement was not observed for the West end of the bridge that was kept restrained throughout all 32 tests, and which was cracked during the initial vertical post-tensioning operation.

Based on the key findings from the experimental program, the following conclusions can be made with regard to the proposed design recommendations by Ramirez and Smith-Pardo (2002):

- Even though the assumption of the participation of diaphragms was confirmed by the experimental values, it did not resulted in a variation of concrete stresses of the magnitude envisioned in the 2002 study.

- The effect of end restraint could not be established with sufficient confidence to indicate a reduction in the concrete deck stresses resulting from the transverse post-tensioning of the same.

- Away from the retrained end of the bridge deck (West side), in the range of post-tensioning estimated to maintain uncracked condition under service loads, the use of uniform transverse post-tensioning is deemed appropriate.

\section{Implementation}

Following the evaluation in the laboratory of the Ramirez and Pardo-Smith (2002) design recommendations for transverse post-tensioning, the proposed next step in the implementation process is to identify a bridge structure in Indiana where uniform transverse post-tensioning of the bridge deck is employed. It is also recommended that the performance of the structure be monitored on a long-term basis. The monitoring plan envisioned would consist of an initial phase during construction and first year of existence, followed by regular monitoring as part of the regular course of Indiana bridge inspection practice.

It is suggested that a bridge with integral end abutments be considered as the field structure and that the deck consists of a cast in-place slab supported on pretensioned bridge girders acting composite with the deck. If diaphragms are employed, it is recommended the use of steel diaphragms. The envisioned instrumentation would consist of strain gages to measure longterm level of prestress force and concrete deck stresses. The gages would be mounted on the transverse deck bars and post-tensioning rods. Embedded sensors in the concrete deck to monitor temperature and humidity, strain gages on the diaphragms and monitoring of deck concrete properties are also recommended. It is proposed that the regular inspection during the initial phase includes cracking and chloride level determinations. It is envisioned that the longterm inspection would include determination of chloride levels and monitoring of transverse posttension force levels. 


\section{Contacts}

For more information:

Prof. Julio A. Ramirez

Principal Investigator

School of Civil Engineering

Purdue University

West Lafayette IN 47907

Phone: (765) 494-2716

Fax: (765)496-1105

E-mail: ramirez@purdue.edu

Indiana Department of Transportation

Division of Research

1205 Montgomery Street

P.O. Box 2279

West Lafayette, IN 47906

Phone: (765) 463-1521

Fax: (765) 497-1665

\section{Purdue University}

Joint Transportation Research Program

School of Civil Engineering

West Lafayette, IN 47907

Phone: (765) 494-9310

Fax: (765) 496-7996

E:mail: jtrp@ecn.purdue.edu 
Final Report

FHWA/IN/JTRP-2010/28

\title{
EXPERIMENTAL EVALUATION AND IMPLEMENTATION OF POST-TENSIONING IN CONCRETE BRIDGE DECKS
}

\author{
by \\ Julio A. Ramirez \\ Principal Investigator \\ Professor \\ School of Civil Engineering \\ Purdue University \\ Gerardo Aguilar \\ Graduate Research Assistant \\ Purdue University
Joint Transportation Research Program
Project No. C-36-56XXX
File No. 7-4-75
SPR-2944 \\ Prepared in Cooperation with the \\ Indiana Department of Transportation \\ and the U.S. Department of Transportation \\ Federal Highway Administration
}

The contents of this report reflect the views of the authors, who are responsible for the facts and the accuracy of the data presented herein. The contents do not necessarily reflect the official views or policies of the Indiana Department of Transportation or the Federal Highway Administration at the time of publication. The report does not constitute a standard, specification, or regulation.

Purdue University

West Lafayette, IN 47906

November 2010 


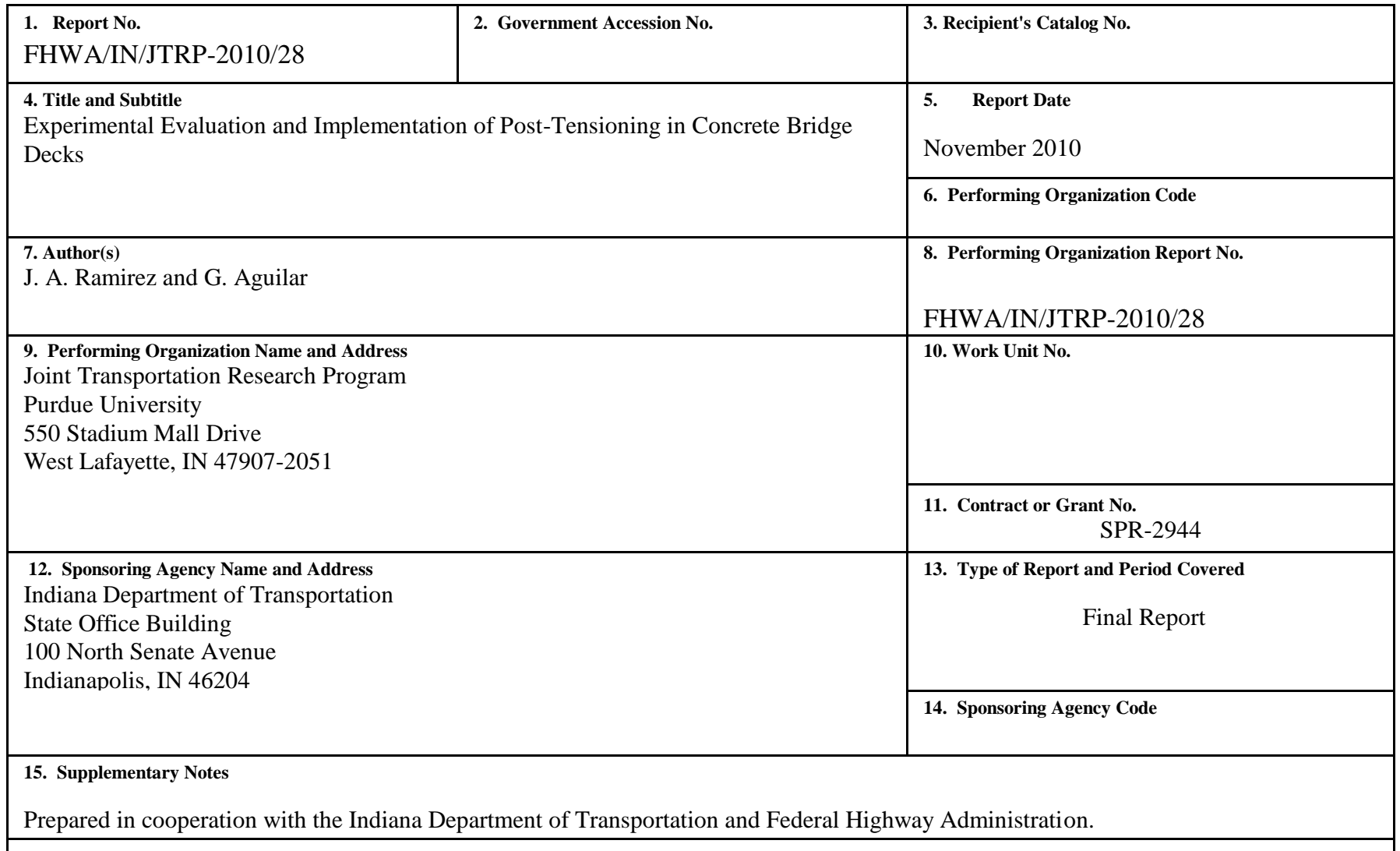

\section{Abstract}

A research program was conducted to evaluate the design recommendations for transverse post-tensioning of bridge decks developed in the FHWA/IN/JTRP/2002-26 (SPR-2409) report. The test specimen consisted of a 40x18 ft cast-in-place concrete deck on precast pretensioned girders. Thirty-two tests were carried out by applying different distributions of transverse post-tensioning force, in combination with a changing number of diaphragms, and two conditions of end-restraint at the supports. The transverse post-tensioning stress ranged from 400 to $1200 \mathrm{psi}$ and the number of diaphragms was reduced from five to zero.

The main findings support the notion that the presence of diaphragms affects the distribution of transverse strains. However, their influence is not as important as analytical models showed. The influence of end-restraint supports on the distribution of transverse strains appeared to be less significant than estimated by Ramirez and Smith-Pardo (2002). Field-work is recommended to further evaluate the effect of this parameter. The use of elastic theory resulted in good agreement between calculated transverse stresses in the concrete deck obtained from the transverse steel reinforcement and those calculated from strains in the post-tensioning bars. In the range of post-tensioning estimated to maintain uncracked condition under service loads, the use of uniform transverse post-tensioning was deemed appropriate.

\section{Key Words}

Bridge deck; cracking; post-tensioning; reinforcement; stress distribution
18. Distribution Statement

No restrictions. This document is available to the public through the National Technical Information Service, Springfield, VA 22161
19. Security Classif. (of this report)

Unclassified
20. Security Classif. (of this page)

Unclassified

21. No. of Pages
46

46 


\section{ACKNOWLEDGEMENTS}

The authors acknowledge the participation of the members of the study advisory committee. The Joint Transportation Research Program of Purdue University in conjunction with the Indiana Department of Transportation and the Federal Highway Administration funded the project. The support from the Indiana Department of Transportation and the Federal Highway Administration through the Joint Transportation Research Program at Purdue University is deeply appreciated. 


\section{TABLE OF CONTENTS}

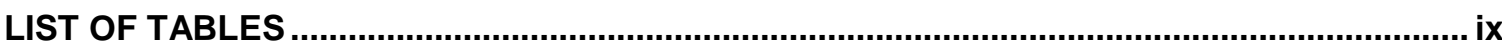

LIST OF FIGURES

CHAPTER 1 INTRODUCTION

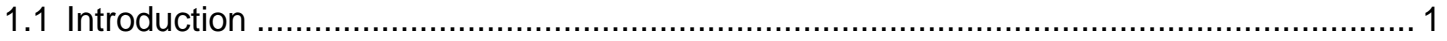

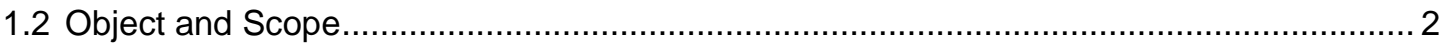

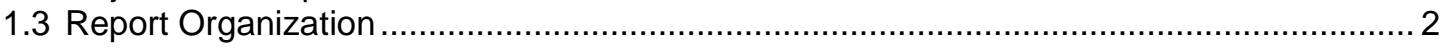

\section{CHAPTER 2 LITERATURE REVIEW}

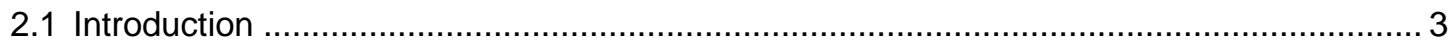

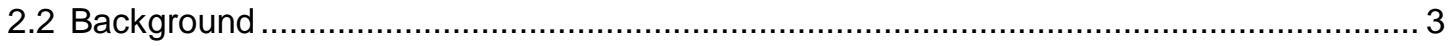

2.3 Review of Multi-phase Research Program at University of Texas ................................. 4

2.4 Review of Ramirez and Smith-Pardo Study (Project SPR-2409) ................................... 7

\section{CHAPTER 3 EXPERIMENTAL PROGRAM}

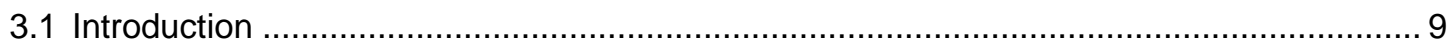

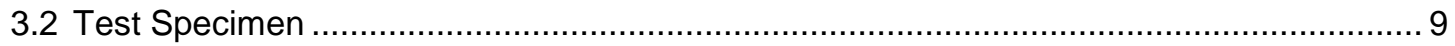

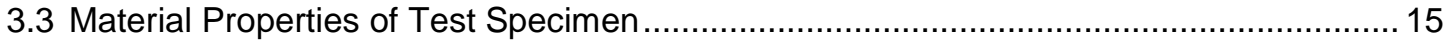

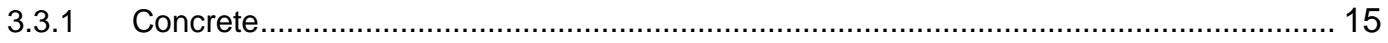

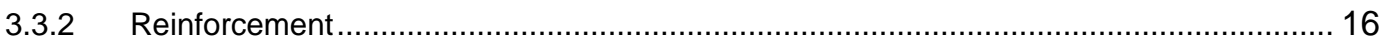

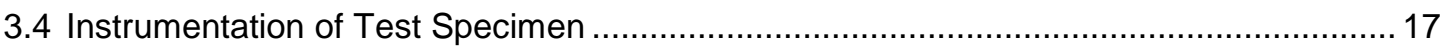



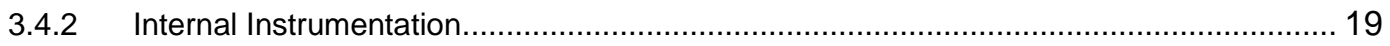

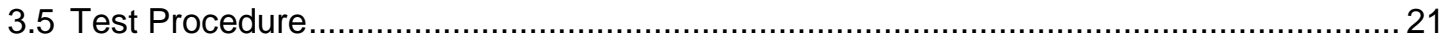

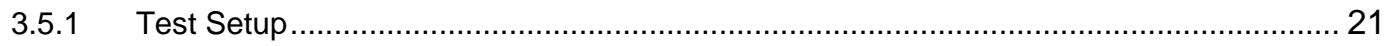

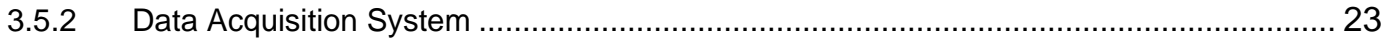

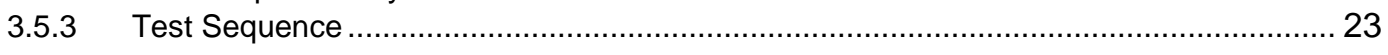

\section{CHAPTER 4 EXPERIMENTAL EVALUATION OF TRANSVERSE POST-TENSIONING}

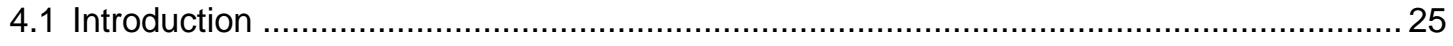

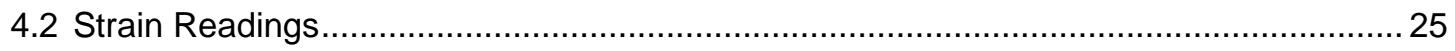

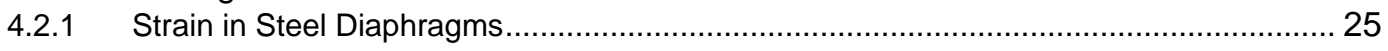

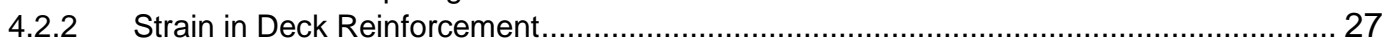

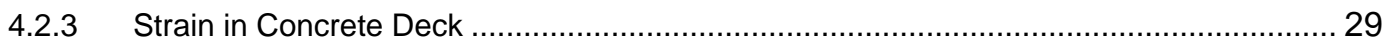

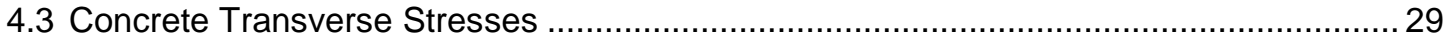

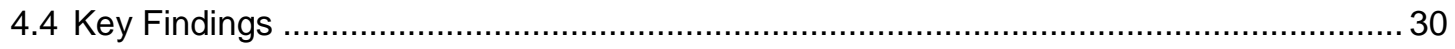

\section{CHAPTER 5 SUMMARY, CONCLUSIONS AND IMPLEMENTATION}

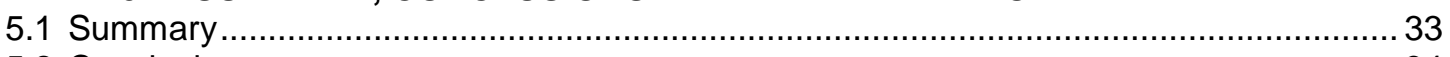

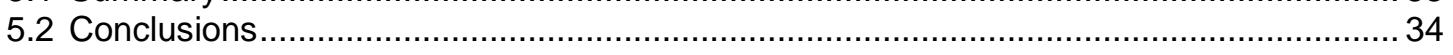

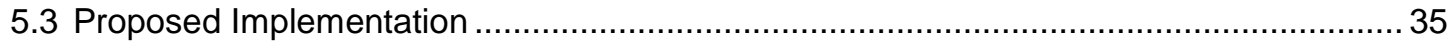

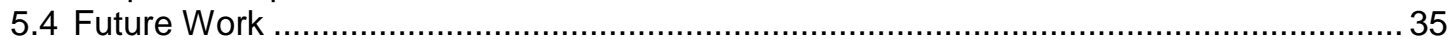

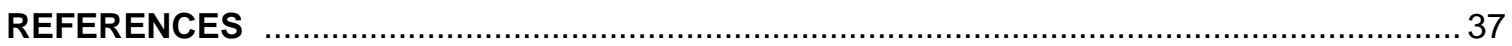




\section{LIST OF TABLES}

Table

Page

Table $3.1 \quad$ Properties of reinforcement of test specimen .................................................. 17

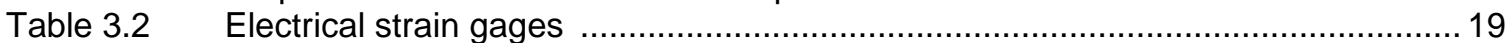

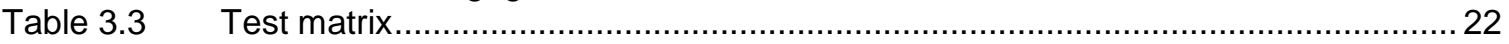




\section{LIST OF FIGURES}

Figure

Page

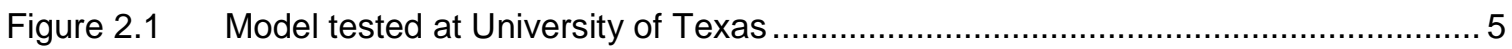

Figure 3.1 Cross section of AASHTO Type I girders ........................................................... 10

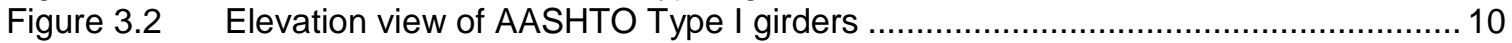

Figure 3.3 Fabrication blueprints for AASHTO Type I girders ............................................ 11

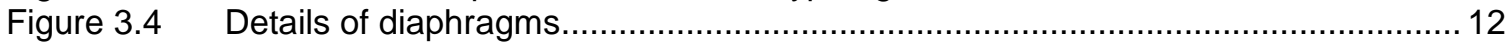

Figure 3.5 General layout of reinforced concrete deck …................................................... 13

Figure 3.6 Sequence of construction of concrete deck .................................................... 14

Figure 3.7 Evolution of concrete compressive strength for AASHTO Type I girders ................16

Figure 3.8 Evolution of concrete compressive strength for concrete deck ............................ 17

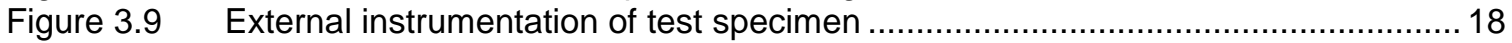

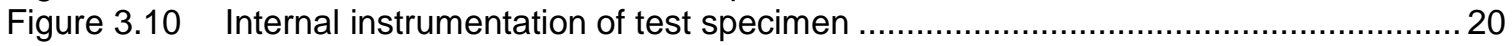

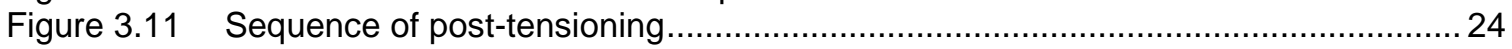

Figure 4.1 Diaphragm strains for tests with two diaphragms and end-restraint at both support lines ............................................................................................... 26

Figure 4.2 Diaphragm strains for tests with two diaphragms and end-restraint at West support line only ........................................................................................... 26

Figure 4.3 Strains in top mat of transverse reinforcement for tests with end-restrain at both support lines ........................................................................................ 27

Figure 4.4 Strains in bottom mat of transverse reinforcement for tests with end-restraint

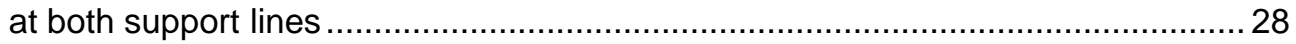

Figure 4.5 Strains in top mat of transverse reinforcement for tests with end-restraint at West support line only ................................................................................... 29

Figure 4.6 Concrete deck stress distribution for tests with end-restraint at both support

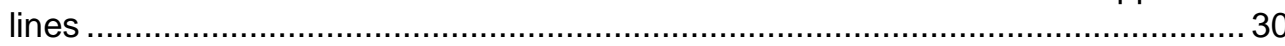




\section{CHAPTER 1 INTRODUCTION}

\section{$1.1 \quad$ Introduction}

The primary bridge maintenance problem in Indiana has been identified as the damage to concrete decks either due to corrosion of reinforcement or freeze-thaw cycles. The use of epoxycoated reinforcement and a minimum thickness of concrete cover have been the primary system for protection against corrosion for the last several decades. However, when the integrity of the epoxy coating is compromised, the initiation of corrosion depends on the chloride concentration at the level of reinforcement. This chloride concentration is directly related to the cracking in the bridge deck. Therefore, the control of deck cracking becomes of paramount importance.

A simple and ingenuous solution to control the cracking of concrete bridge decks, effectively improving their durability, was suggested by Tedesko (1976) and Blaha (1980) through the use of prestressing. Poston et al. (1987) observed that the use of transverse prestressing resulted in controlling the extent of cracking and thus preventing the penetration of chloride ions to the reinforcement level. The main benefit observed by Poston et al. for a transversally prestressed bridge deck was the elimination and control of cracking, which restrict the penetration of all water, chloride and oxygen, thus extending the life of the bridge.

In the FHWA/IN/JTRP/2002-26 (SPR-2409) report, design expressions for the use of transverse post-tensioning were developed based on extensive analytical studies (Ramirez and SmithPardo, 2002). Experimental results from previous research programs -particularly that of Poston et al. (1987)- were used to validate the design specifications.

In the Ramirez and Smith-Pardo (2002) Report emphasis was placed on the development of design guidelines for the application of transverse post-tensioning force along the deck edge required to meet desirable levels of compression stresses on its top surface. It was recommended that different application levels of prestressing were required in regions containing interior and exterior (or outermost) diaphragms. It was also concluded that the magnitude of such transverse forces primarily is a function of the girder's boundary conditions, the axial stiffness of the diaphragms, the skew angle of the deck, and the position of the diaphragms/stiffeners with respect to the edge of the deck. The parametric study also revealed that the use of transverse post-tensioning in integral bent spans could have limited effectiveness in the region adjacent to integral supports. 
The design specifications developed in the Ramirez and Smith-Pardo (2002) report were preliminary and not proposed for immediate use until the key modeling assumptions in the parametric study were tested in the laboratory and a subsequent field phase consisting of the monitoring of a pilot structure. The research program described in this report addresses the first recommendation of Ramirez and Smith-Pardo (2002).

\section{$1.2 \quad$ Object and Scope}

The main objective of this research project is to evaluate in the laboratory the key modeling assumptions of the analytical study conducted by Ramirez and Smith-Pardo (2002), and their recommendations on distribution of stress in concrete bridge decks resulting from transverse post-tensioning.

The experimental program documented in this report was put together and conducted to achieve the previously stated objective. A rectangular concrete bridge deck supported on precast prestressed concrete girders was built and 32 tests were conducted with it. The key parameters of the study were the effect of both girder boundary conditions and position of the diaphragms. The number of steel diaphragms was varied from five to none, and the applied transverse stress from 400 to $1200 \mathrm{psi}$. Also, the restrain force at one of the support lines was varied to evaluate the effect of end-restraint on the distribution of transverse post-tensioning. Due to laboratory limitations, the effect of the angle of skew of the deck was not evaluated. An analysis of the results of the experimental program, focused on the validation of the findings of Ramirez and Smith-Pardo (2002), is also presented.

\section{$1.3 \quad$ Report Organization}

This report consists of five chapters. Chapter 1 provides the background and the scope of the study. Chapter 2 provides a brief literature review of previous relevant experimental works and the analytical work conducted by Ramirez and Smith-Pardo (2002). Chapter 3 describes the experimental program of this study, with information on the materials used in the construction of the test specimen, design, geometric properties, construction sequence, instrumentation, and testing protocols. In Chapter 4, the experimental results are summarized together with the analysis of the data. The key findings and recommendations for implementation are given in Chapter 5 together with a brief summary of needed future work. 


\section{CHAPTER 2 LITERATURE REVIEW}

\section{$2.1 \quad$ Introduction}

This chapter presents a summary of the experimental and analytical work carried out at the University of Texas during the 80's. A brief description of the salient aspects of the Ramirez and Smith-Pardo (2002) study is also given, including a discussion of the general behavior of bridge decks with transverse post-tensioning.

\section{$2.2 \quad$ Background}

The determination of the state of stress and strain within a concrete bridge deck subjected to transverse post-tensioning is a difficult one due to effects associated with geometry, support and boundary conditions, presence of diaphragms, and changes in stiffness of the elements of the bridge. The simplest application of transverse forces to prevent and control cracking is through a uniform compressive stress along the boundary of the deck. However, the presence of disruptive elements, such as boundary members and diaphragms, causes the compressive stress in the deck not to be uniform despite the uniform application of edge post-tensioning force. In order to compensate for the presence and effects of these elements, the transverse post-tensioning forces applied to the deck often will have to be non-uniform.

The behavior and analysis of concrete bridge decks can be divided into elastic and inelastic. At low levels of load, is plausible to analyze the behavior of the deck using elastic theory, which assumes that equilibrium is satisfied at every point; the material is isotropic and behaves in a linearly elastic fashion; deformations are small with respect to the thickness of the deck, and inplane sections may reasonably be assumed to remain plane after bending. Once the load increases, cracking of the concrete progresses and, at higher load levels, inelastic behavior of the deck develops. Throughout the research project described in this report, the level of strain and stress in the concrete deck is kept below the elastic limit.

Transverse post-tensioning was empirically implemented in Europe during the 60's. According to Almustafa (1983), the main objectives pursued were: a) maximize the length of overhangs in boxgirders, b) maximize the number of webs in cell-box girders, c) improve connection between

girders, and d) provide better reinforcement layout at supports. Associated with the construction 
of a twin-steel-girder expressway bridge in Dallas, a large multi-phase research project was conducted at the University of Texas (Poston et al. 1985).

\subsection{Review of Multi-phase Research Program at University of Texas}

Most of the experimental evidence and analytical background used in the design and construction of bridge decks with transverse post-tensioning emerged from a multi-phase and very thorough research program conducted at the University of Texas during the 80's. A series of publications, reports and papers was developed and they summarize the work carried out during a span of about seven years. More details on the information presented next may be found in Almustafa (1983), Mora (1983), Phipps (1985), Poston (1984), Poston et al. (1985, 1987, 1989), Ralls (1984), and Randall et al. (1988).

The research program at the University of Texas comprised an analytical study and an experimental program. During the analytical study, a series of finite element models of the entire superstructure including deck, girders, and diaphragms was developed to study the distribution of stresses within the deck due to transverse post-tensioning. The main findings from this study were the following:

- Distribution of stress depends highly on the presence of diaphragms.

- Restraining effect of girders is greatly reduced if supported on flexible (elastomeric) supports.

- Support conditions significantly impact the distribution of stresses within the deck.

For the experimental phase, a prototype structure was built and tested. The structure was nearly half scale deck-on-girder bridge which consisted of a 8.25-in. thick, 76-ft span and 58-ft wide deck supported by seven girders. The girders were standard Texas Type $\mathrm{C}$ precast, pretensioned elements spaced at $8.83 \mathrm{ft}$. Two exterior concrete diaphragms composite with the deck and two interior concrete diaphragms supported by the bottom flange of the girders were included in the first phase of testing. The interior diaphragms, located at third points of the span, were removed in the second phase of testing. The first phase considered an all-diaphragm case while the second phase represented an end-diaphragm case. Figure 2.1 shows the model tested at the University of Texas.

The transverse post-tensioning was provided by means of strands instrumented at the live-end only. Both, straight and draped tendons were used to evaluate the relative effectiveness of each. Half of the model was postensioned using straight tendons only while the other half had both straight and draped tendons. Only one half of the model was postensioned at a given time. The model was instrumented with strain gages placed at top and bottom of the deck. 


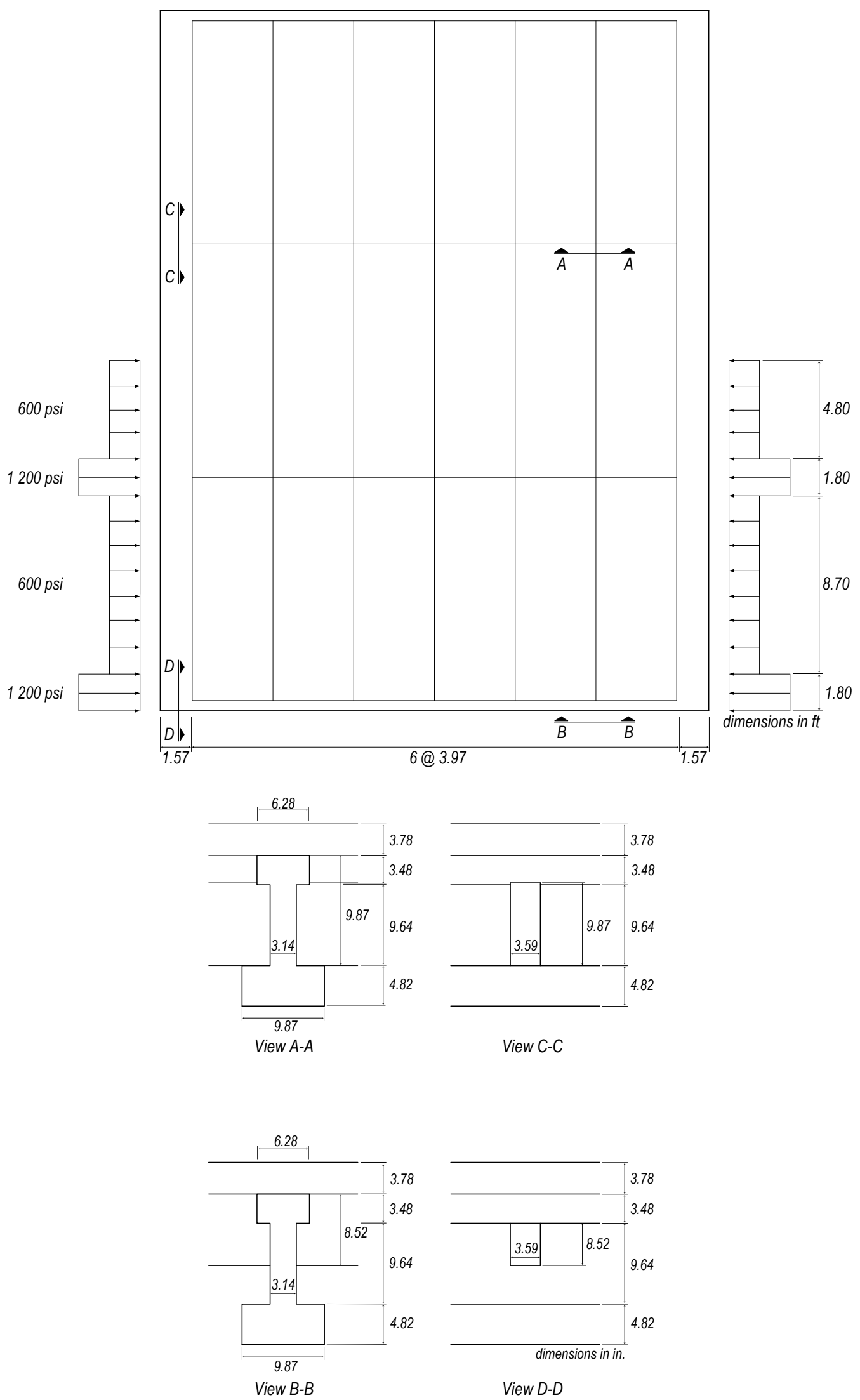

Figure 2.1 Model tested at University of Texas 
The most relevant findings of the experimental study were the following:

- Jacking sequence did not have a significant impact on the distribution of stresses.

- Restraining effect of diaphragms is limited to the deck region adjacent to them.

- Restraining effect of girders is confined to a very narrow strip of the deck, right above the girders.

- A region of compressive stresses was found between points of application of transverse post-tensioning. The size of the region was proportional to the distance between tendons.

- There was reasonable agreement between the results of the analytical study and those of the experimental study. Differences were less than $15 \%$ on average (Almustafa, 1983).

Using the findings in the analytical and experimental studies, design recommendations were developed. They were formulated on the premise that the response of the superstructure under service loads would remain linear elastic, and that the stresses induced by service loads are known from conventional analysis. Recommendations were given to provide a compressive stress on top of the deck that prevented cracking at service load levels. It was also stated that additional transverse post-tensioning was required at diaphragm regions to compensate for their restraining effect. The additional transverse post-tensioning ranged from 20 to $60 \%$ of that which was needed to resist the effects of imposed service loads assuming no restraining effects. The diaphragm region was defined as a strip of at least $4 \mathrm{ft}$ increasing with the skew angle of the deck.

Additional design recommendations proposed by the researchers at the University of Texas included the provision of shrinkage and temperature reinforcement as specified in conventional design; the provision of transverse mild reinforcement to control crack propagation when unbonded post-tensioning is used; a crack-free design in the longitudinal direction of the deck; and the limitation of the edge prestressing stress to a concrete tensile stress at service load level of $2 \sqrt{f^{\prime}}$.

The minimum protection scheme against corrosion in the longitudinal direction was suggested to comprise at least one of the following items: a) use of epoxy-coated reinforcement, b) posttensioning of the deck in the support region, or c) draping of post-tensioning in the top part of the deck. In order to prevent splitting failures associated with multiple in-line anchorage zones, it was recommended not to place straight tendons in a single row. The maximum spacing between posttensioning strands was suggested to be controlled by the prevention of shear lagging and by the avoidance of truckloads acting in regions of the deck between points of application of posttensioning.

Finally, the use of draped tendons was discouraged because of the likelihood of accidental eccentricities to occur. A small placement error of $0.25 \mathrm{in}$. resulted in a change of transverse 
moment of about $18 \%$. Also, friction losses were observed to be more significant and labor costs due to extra time and effort for placing draped tendons increased.

\subsection{Review of Ramirez and Smith-Pardo Study (Project SPR-2409)}

Ramirez and Smith-Pardo (2002) conducted a study at Purdue University concerning the development of design specifications for the use of transverse post-tensioning in concrete bridge decks. Experimental results from the University of Texas study summarized in Section 2.3 were used to evaluate the analytical models developed.

The experimental results obtained during the University of Texas multi-phase research program were used to evaluate the analysis results from 2D and 3D finite element models. A 2D finite element analysis places all deck, girders and diaphragms on the same plane, which implies that there are stripes of the deck where stiffness concentration due to the presence of diaphragms occurs (Mabsout et al., 1999). In 2D models, the eccentricity of the post-tensioning force with respect to the superstructure elements is ignored. In contrast, in a 3D model, the elements of the superstructure are placed on different planes, according to their own geometry. Also, any effect of the eccentricity of the prestressing force is taken into consideration.

Three-dimensional modeling for deck-on girder bridges can be distinctively divided into three techniques (Bishara and Elmir, 1990; Bishara et al., 1993; Mabsout et al., 1997; Chan and Chan, 1999):

a) Girders and diaphragms are modeled as frame elements rigidly connected to the deck.

b) Flanges and webs of girders are modeled as frame elements, diaphragms are modeled as shell elements. Adjacent elements are connected rigidly to each other.

c) Compression flanges of girders and diaphragms are modeled as frame elements rigidly connected to the deck, tension flanges of girders are modeled as frame elements and webs of girders are modeled as shell elements.

Ramirez and Smith-Pardo developed one 2D model and the three types of 3D models listed above. The analysis results showed that the average difference between experimental and analytical values of stress at various locations of the deck was in the range of 10 to $43 \%$. The 3D model showed a slightly better performance, with average differences in the range of 14 to $36 \%$. The largest differences were observed while modeling the second phase of the University of Texas experiment, where interior diaphragms had been removed and only end diaphragms were in place.

The Ramirez and Smith-Pardo (2002) study included also a parametric analysis to identify the most relevant variables and their effect on the distributions of transverse stresses. A base case 
structure similar to the one tested at the University of Texas was analyzed and the effect of girders, boundary conditions, spacing of post-tensioning, deck thickness, and size and position of diaphragms was determined. The parametric study allowed for the derivation of a simple design procedure that required the computation of factors that increased the magnitude of the desired compressive stress at the top of the deck to account for the presence of diaphragms and boundary elements. These factors, ranging form 1 to 6 , are to be computed at exterior diaphragm regions, at interior diaphragm regions, and at intermediate regions (between diaphragms). Ramirez and Smith-Pardo (2002) proposed two sets of graphic design aids, one for concrete girder bridges and another for steel girder bridges.

The study showed that the required distribution of post-tensioning force was directly influenced by the position and size of diaphragms. Furthermore, girder boundary conditions, axial stiffness of diaphragms, skew angle of deck, and relative position of diaphragms with respect to the deck influenced the magnitude of post-tensioning forces. Support and boundary conditions for girders and deck limited the displacements in the transverse direction, thus changing the distribution of transverse stresses.

In the case of bridges with integral bent spans, the researchers observed that the use of transverse post-tensioning was not as effective as in the case of bridges with non-integral abutments. Another case where the use of transverse post-tensioning may not be effective, up to the point of being detrimental because of inducing tensile stresses at the top of the deck, was in bridges with skew angles larger than 20 deg. 


\section{CHAPTER 3 EXPERIMENTAL PROGRAM}

\subsection{Introduction}

This chapter presents a detailed description of the testing program. The main objective of the program was to evaluate the adequacy of design aids developed by Ramirez and Smith-Pardo (2002). The properties of the materials used in the construction of the test specimen are given together with construction details, test setup, instrumentation and test procedure. The distribution of stresses in the deck was evaluated under different configurations of transverse posttensioning. The effect of diaphragms and end restraint were also studied. Throughout the tests, the level of stresses was kept in the linear elastic range of the materials.

\subsection{Test Specimen}

Geometry, reinforcement details and constructions processes are described next. These items are covered in two categories: a) prestressed concrete girders, and b) reinforced concrete deck. It was also necessary to cast twelve concrete blocks to support the bridge. These are described in section 3.5.1.

The test specimen consisted of a cast-in-place concrete deck on precast pretensioned girders. The dimensions were established on the basis of the most frequent values registered in the 2002 database of prestressed concrete bridges in Indiana, and considering the lifting capacity of the 30ton overhead crane at the Robert L. and Terry L. Bowen Laboratory for Large-Scale Civil Engineering Research at Purdue University. It was decided that a 40-ft long, 18-ft wide and 8-in. thick deck was representative of a section of a state road bridge in Indiana. The deck was supported on three AASHTO Type I prestressed girders. In order to make comparisons between the behavior of interior and exterior girders, all had the same tributary width of $6 \mathrm{ft}$. The girders rested on reinforced concrete support blocks that allowed the access underneath the deck.

The girders were cast at the plant of Prestress Services Inc. of Decatur, Indiana and were densely instrumented with electrical strain gages. The three girders supporting the deck were AASHTO Type I. Figure 3.1 shows the typical cross section of the girders. The total depth of the girders was $28 \mathrm{in}$., the top flange was 12-in. wide and the bottom flange was 18-in. wide. Web thickness was $6 \mathrm{in}$. The cross section was the same throughout the length of the girders. The area of the cross section was $276 \mathrm{in}^{2}$. 


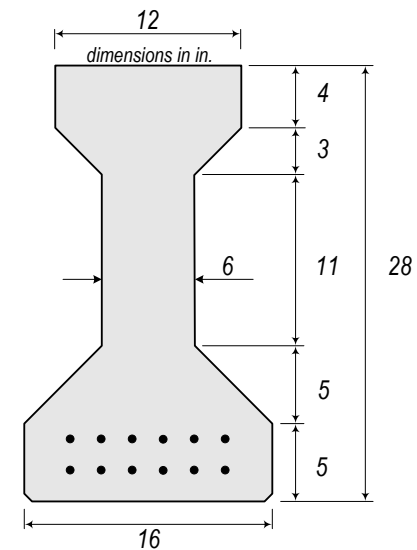

Figure 3.1 Cross section of AASHTO Type I girders

The total length of the girders was $40 \mathrm{ft}$. A 3-ft long overhanging past the support line was provided to account for proper transfer of prestress force and to avoid shear tension failures. Therefore, the clear span between support lines was $34 \mathrm{ft}$. Figure 3.2 shows an elevation view of the AASHTO Type I girders.

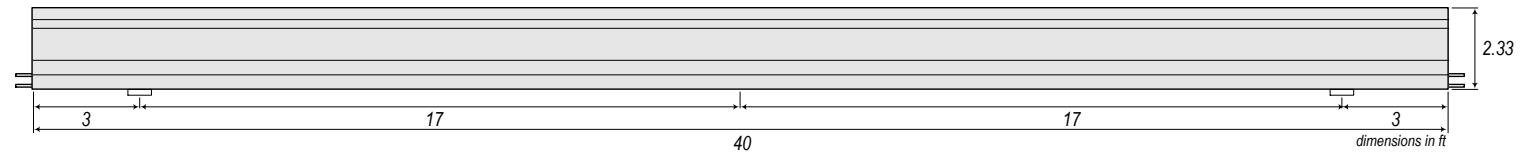

Figure 3.2 Elevation view of AASHTO Type I girders

All girders had the same longitudinal reinforcement: Two No. 6 bars in the top flange and twelve strands distributed in two rows in the bottom flange. Mild reinforcement was straight and continuous through the length of the girders. All mild reinforcement was Gr.60. Prestressing steel consisted of 1/2-in. special (oversized) seven-wire low-relaxation, uncoated prestressing strands. Twelve strands were located in two layers of six strands each. Ultimate strength of the strands was $270 \mathrm{ksi}$. Shear reinforcement was provided by means of No. 3 inverted-U stirrups. All girders had stirrups spaced at $12 \mathrm{in}$. Stirrups were made with Gr.60 steel. Additional reinforcement for cage fabrication was provided with No. 3, Gr. 60 steel. Bottom flange reinforcement was provided at both ends of the girders by means of four No. 3 bars spaced 12-in., and bent to the shape of the flange. All mild reinforcement was tack welded together to form the steel cages. Figure 3.3 shows the fabrication blueprints of the girders.

A small tension force of $3000 \mathrm{lb}$ was applied to the twelve strands of the girders to avoid tangling. Then, the two strands that were to be instrumented with electrical strain gages were tensioned to the specified force $(33818 \mathrm{lb})$ and the corresponding locations for strain gages marked. After this was done, these two strands were detensioned and allowed to rest on the prestressing bed. After the instrumentation of these strands was concluded, the reinforcing cages were brought into the prestressing bed. Additional time was allotted to run the wires of the electrical strain gages from each instrumented location to various output ports. Then the forms were placed in their final position and all strands were tensioned to the specified force. 


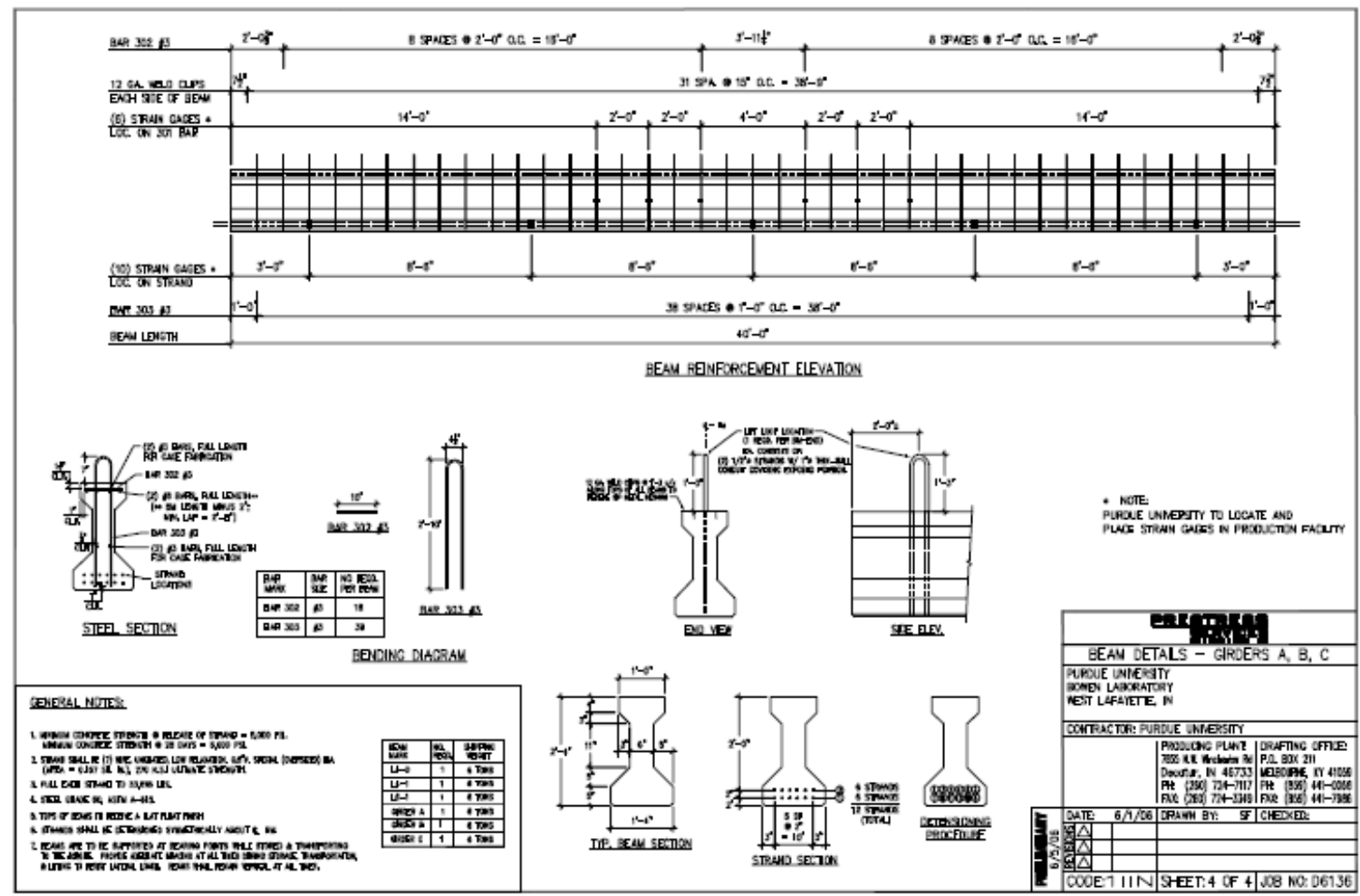

Figure 3.3 Fabrication blueprints for AASHTO Type I girders

All three girders were cast on the same day using the same concrete mix for a nominal compressive strength of $6000 \mathrm{psi}$. Girders were labeled Girder A, Girder B and Girder C. The order of casting was Girder C, Girder B, and Girder A. As the casting progressed, concrete samples were taken. Twelve $6 \times 12$-in. cylinders were sampled for each girder using new plastic molds. Steel rods were used for the consolidation of samples. After casting, the prestressed concrete girders were covered with plastic for two days. The concrete strength and temperature were monitored during that period. Once the compressive strength of concrete had reached $5000 \mathrm{psi}$, the transfer or prestress was done by flame-cutting the strands with oxyacetylene torch. Girders were removed from the prestressing bed and placed in a storage area for two days. The untwisted wires at the end of prestressing strands were ground 6 in. away from the end faces. A week after the cast, the girders were shipped to the Robert L. and Terry L. Bowen Laboratory for Large-Scale Civil Engineering Research at Purdue University, where they were air cured until the construction of the deck started.

Upon arrival to the Bowen Laboratory, the girders were set on top of reinforced concrete blocks. Elastomeric supports 14" $x 7$ "x2-1/2" provided by the Indiana Department of Transportation (INDOT) were set directly in between the support blocks and the girders. Section 3.5.1 of this report provides more details on the test setup. Perforations of 1-in. diameter were drilled through the web of the girders at various locations in order to allow for the attachment of steel diaphragms. Five sections with steel diaphragms were used. A maximum of ten identical diaphragms were installed. Diaphragms were made with a W8x21 section of A36 steel. Twenty steel clip angles 
( $L 6 " x 4 " x 1 / 2 ")$ were used to support the diaphragms. The geometry of diaphragms was based on the design indicated by INDOT for AASHTO I-beams in drawing E 707-B-173d. These drawings were provided by Greg Klevitsky, from INDOT. The design of diaphragms was based on obtaining a similar axial stiffness of the typical concrete diaphragm used for AASHTO Type I bridge girders. Total depth of diaphragms was limited to $8 \mathrm{in}$. as they were to be used as part of the shoring system during the casting operation of the deck, which required the setting of 6-1/2 in. high Aluma beams spanning from diaphragm to diaphragm. Figure 3.4 shows the details of the diaphragms.


\section{Figure 3.4 Details of diaphragms}

It must be noted that INDOT recommendations do not call for steel diaphragms for bridges with AASHTO Type I girders. However, as it was one of the goals of this project to study the effect of the number of diaphragms on the distribution of transverse stresses, it was decided that removable steel diaphragms were more adequate than concrete diaphragms. 
Steel diaphragms were attached to the girders by means of $G r .8$ ( $\left.F_{u} \geq 150 \mathrm{ksi}\right), 9$ - and 3-1/2-in. long, high-strength hex head 7/8-in. diameter bolts. A total of 70 bolts were needed. Steel plate washers, SAE hardened washers and Gr. 8 hexagonal (full) nuts were used as indicated by INDOT. Snug tightening by means of a pneumatic gun was carried out on each bolt after hand tightening by means of a wrench.

Next, a cast-in-place concrete deck was built on top of the three girders. The deck was densely instrumented by means of electric strain gages attached to the reinforcement and embedded in the concrete. The bridge deck was 40-ft long, 18-ft wide, and 8-in. thick. Nineteen cubic yards of concrete were used on the deck. Some 3-1/4 in. diameter perforations were provided by means of PVC pipe to allow for the location of vertical post-tensioning bars in the support regions. The ducts for the transverse post-tensioning of the deck were provided by means of 2-in. diameter PVC pipe. They were spaced $1 \mathrm{ft}$. in the longitudinal direction of the bridge deck. Figure 3.5 shows the general layout of the bridge deck.

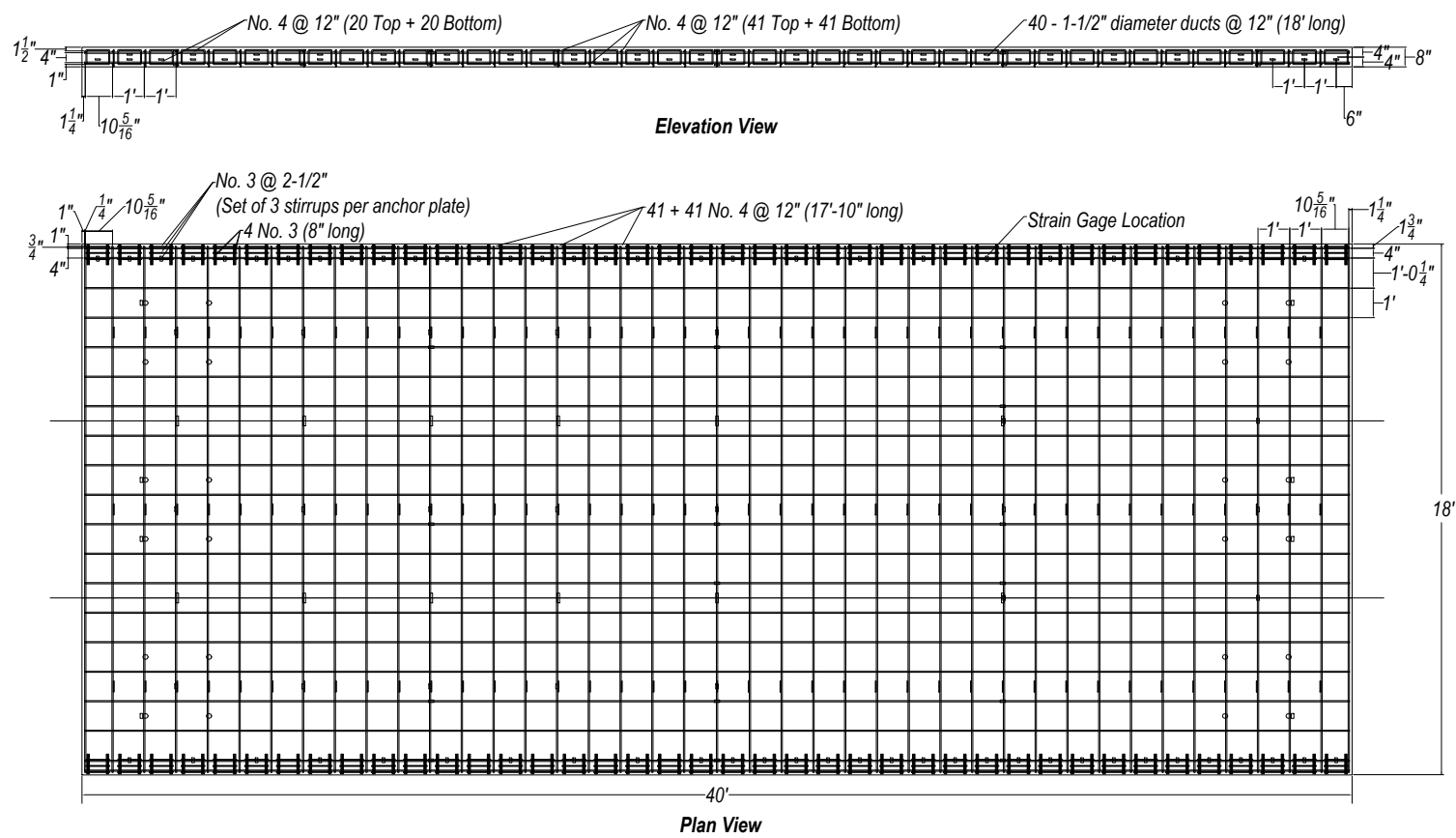

Figure $3.5 \quad$ General layout of reinforced concrete deck

The reinforcement of the bridge deck was distributed in two identical mats made with No. 4, Gr. 60 epoxy-coated reinforcement. Reinforcement was continuous, straight, and spaced 12 in. in both directions. Clear cover to the top face of the deck was 1-1/2 in., and clear cover to the bottom face was 1 in. Additional reinforcement was provided at both longitudinal edges of the deck to prevent damage due to the bursting forces associated with the transverse post-tensioning. This reinforcement, also epoxy-coated, was located at every post-tensioning location and consisted of a set of three No. 3, 9x6-in. rectangular stirrups at a 2-1/2 in. spacing. The stirrups were kept in place by means of four No. 3 bars located at their corners. Recommendations by Dywidag-Systems 
International were used, which were in full compliance with the $\mathrm{ACl} 318-08$ Building Code $(\mathrm{ACl}$ Committee 318,2008 ) requirements for bursting reinforcement in a disturbed region.
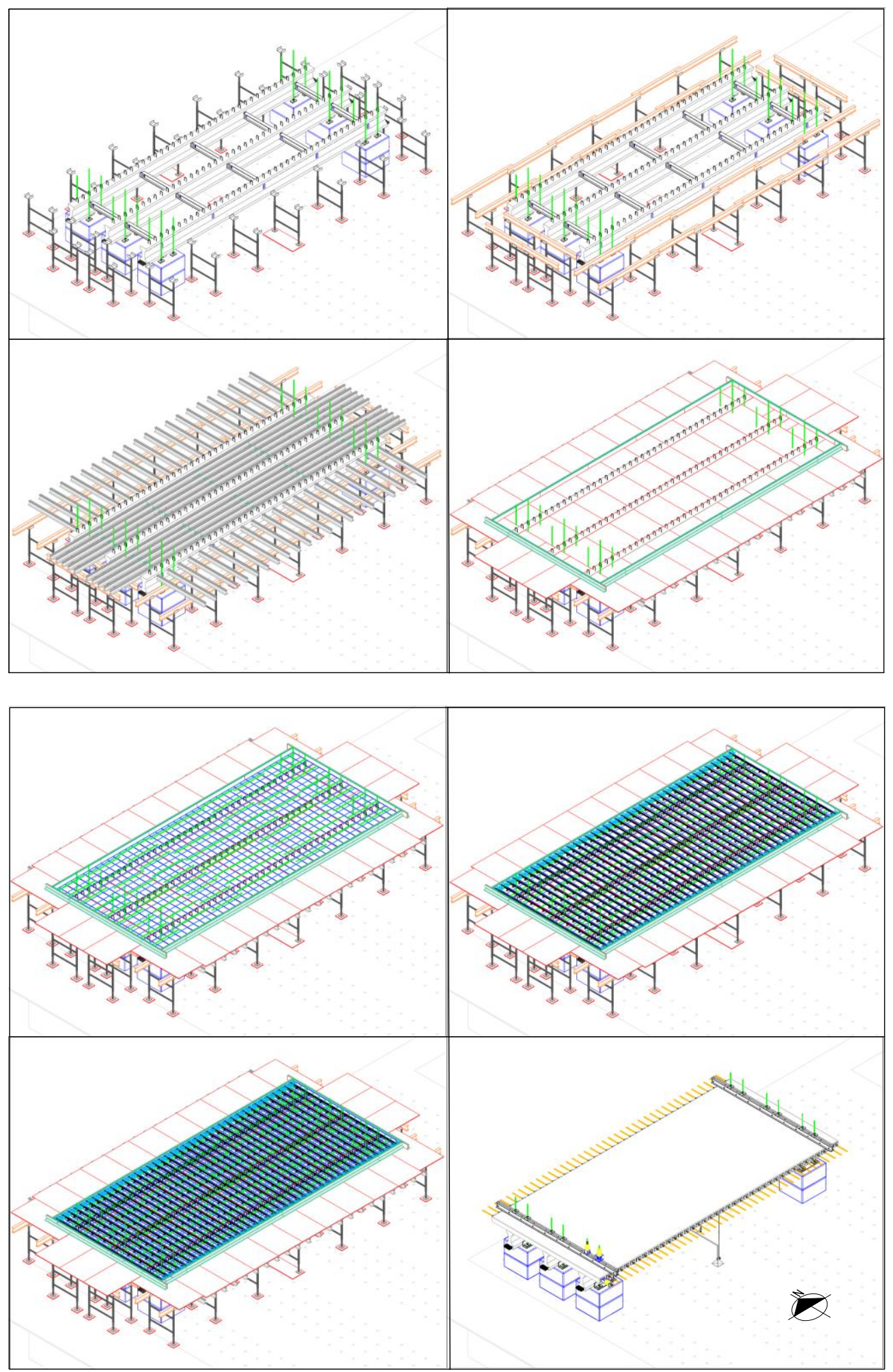

Figure 3.6

Sequence of construction of concrete deck 
Post-tensioning of reinforced concrete deck was provided by high strength (Gr. 150) Dywidag bars 1-1/4 in. diameter, and $22 \mathrm{ft}$ long. Similar post-tensioning bars were used vertically to provide the restrain required at support lines. In total, forty ducts spaced $12 \mathrm{in}$., were located along the bridge deck. Sketches of the sequence of construction are shown in Figure 3.6.

The bottom mat of reinforcement was placed in the form and directly on top of 1-in. high chairs. Then, the 2-in. diameter PVC pipe required for the transverse post-tensioning was set on 3-1/4-in. high chairs, and the bursting reinforcement placed with it. The location of the PVC pipe was done in a way that, once the post-tensioning bars rested inside it, the centroid of the bars coincided with the mid-height point of the deck. It was noticed that the setting of rectangular cages of bursting reinforcement was cumbersome. It is recommended that bursting reinforcement is provided in the form of spirals. Once the PVC was in place, the top grid of reinforcement was laid out by using, once again, chairs. After all reinforcement was set, the wires of electric strain gages were run to various outlets. All outlets were on the bottom face of the deck. Strain gage wires were guided along the reinforcement by means of plastic ties.

Casting of the deck required $19 \mathrm{yd}^{3}$ of concrete, which were provided by means of two $9.5 \mathrm{yd}^{3}$ mixing trucks. The concrete mix was a 7 bag mix, which has a nominal compressive strength of 6000 psi. It was provided by Irving Materials Inc. of West Lafayette, Indiana. The cast operation was conducted with the help of Midwest Concrete Pumping and Concrete Construction of Indianapolis, Indiana. The operation took about four hours to be completed and involved the use of a concrete pump truck. Once the concrete deck had hardened, curing compound CS 309-25 manufactured by W.R. Meadows, Inc. was applied by means of a roller throughout the surface.

\subsection{Material Properties of Test Specimen}

Materials used in the construction of the test specimen were sampled and tested to determine their properties. This section presents the results of the testing of these materials.

\subsubsection{Concrete}

The girders of the test specimen were constructed at the Prestressed Services, Inc. plant in Decatur, Indiana. All of them had a nominal concrete strength of 6000 psi. Twelve $6 \times 12-i n$. cylinders were sampled for each girder using new plastic molds. Six cylinders were used to determine the evolution of concrete compressive strength and the rest were used to determine the compressive strength at the test dates. Slump tests (following ASTM C 143-05) and air content tests (following ASTM C 231-04) were also carried out during the casting operation. Average slump for all three girders was $5 \mathrm{in}$. Air content ranged from 4.5 to $6.3 \%$. Sampled concrete cylinders were transported to the laboratory and air-cured until their corresponding test date following ASTM C 192-05. 
The compressive strength of concrete was determined using the procedure of ASTM C 39-04 and ASTM C 1231-00 for cylinders with unbonded caps. Loading rate was set at $2100 \mathrm{psi} / \mathrm{min}$ throughout the tests. The evolution of concrete compressive strength for each of the girders is presented in Figure 3.7. The average compressive strength of concrete at test date was 10070 , 8 240, and 5227 psi for Girder A, Girder B and Girder C, respectively.

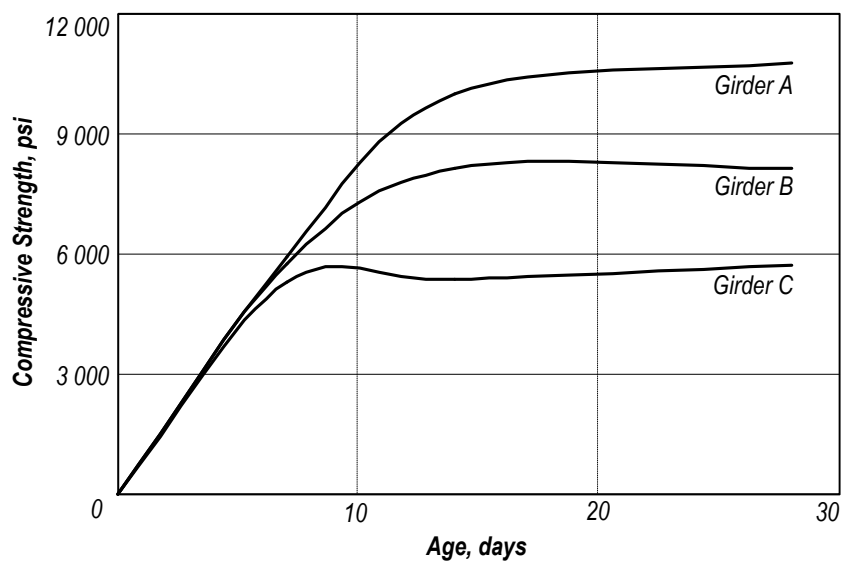

Figure 3.7 Evolution of concrete compressive strength for AASHTO Type I girders

The concrete deck was cast on top of the girders at the Robert L. and Terry L. Bowen Laboratory for Large-Scale Civil Engineering Research using the services of Reynolds, Inc. from Indianapolis, Indiana. The nominal compressive strength of concrete was 6000 psi. Sampling of concrete during the cast involved taking thirty-two $6 \times 12$-in. cylinders to determine the evolution of compressive concrete strength. The slump, measured at the beginning of the cast, was $4 \mathrm{in}$. Figure 3.8 shows the evolution of concrete compressive strength of the deck. Each curve in Figure 3.8 corresponds to a set of samples taken around the same time during the process of casting. On the test date, the average compressive strength of the concrete of the deck was 5405 psi.

The concrete used in the fabrication of the concrete support blocks was also sampled for testing. The slump, measured at the beginning of the casting operation was $6.5 \mathrm{in}$. The average concrete compressive strength of these blocks, measured at 28 days, was $6100 \mathrm{psi}$.

\subsubsection{Reinforcement}

All mild reinforcement used in the girders and the deck was ASTM A 615-05. The mechanical properties of the reinforcement used in the fabrication of the girders and the deck were obtained from mill reports and through tension coupon tests. The properties of the reinforcement, including elongation, were determined from 36-in. long coupons. Tension coupons were obtained form the same bars used in the fabrication of the deck, and all came from the same heat. ASTM A 370-05 Standard was followed throughout the test of coupons. 


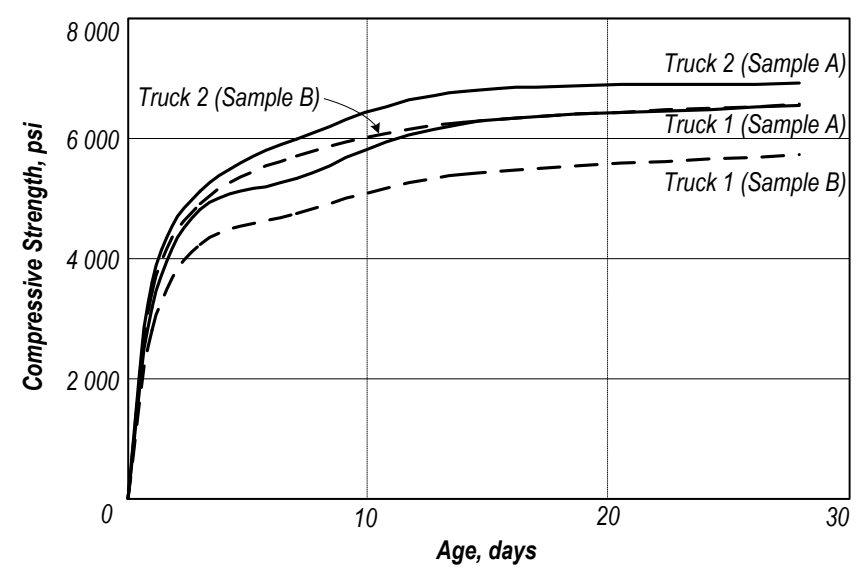

Figure 3.8 Evolution of concrete compressive strength for concrete deck

In order to measure strain in the tension coupons, a 2-in. gage extensometer (MTS ${ }^{\circledR}$ Model 634.25E-54). All tests were conducted in a 200-kip 4-pole MTS testing machine with displacement control. A single, continuous loading rate of $0.75 \mathrm{in} / \mathrm{min}$ was used throughout the tests. The testing machine had a precision of $10 \mathrm{lb}$ and $0.0001 \mathrm{in}$. Table 3.1 summarizes the properties of the reinforcement used in the construction of the test specimen.

The post-tensioning forces were applied using Dywidag-Systems International Threadbar ${ }^{\circledR}$. These are Gr. 150 high-strength alloy steel bars. Forty 1-1/4 in. diameter bars were used for the transverse post-tensioning of the deck. Twenty-four additional bars of the same diameter were used to apply the restrains at support lines.

Table 3.1

Properties of reinforcement of test specimen

\begin{tabular}{cccc}
\hline Type of reinforcement & Size & $\boldsymbol{f}_{\mathbf{y}, \boldsymbol{k s i}}$ & $\boldsymbol{f}_{\boldsymbol{u}}, \boldsymbol{k s i}$ \\
\hline Longitudinal reinforcement (girders) & No. 6 & 74.8 & 111.7 \\
Shear reinforcement (girders) & No. 3 & 69.0 & 101.9 \\
Prestressing reinforcement (girders) & 1/2-in. special strand & 261.4 & 283.7 \\
Mild reinforcement (deck) & No. 4 epoxy-coated & 66.1 & 99.2 \\
Bursting reinforcement (deck) & No. 3 epoxy-coated & 73.0 & 111.9 \\
Post-tensioning reinforcement (deck) & 1-1/4-in. Dywidag Threadbar & \\
\hline
\end{tabular}

\subsection{Instrumentation of Test Specimen}

The instrumentation of the test specimen was divided in two general categories: a) external instrumentation, and b) internal instrumentation. Instrumentation was located at relevant points of the test specimen with the objective of studying its local and general behavior. The devices that were used were linear variable differential transformers (LVDTs), inclinometers, wire potentiometers, and electrical strain gages. The location and type of instrumentation allowed for measuring the vertical displacement of the girders, their rotation at supports, the relative 
displacement between girders, the applied post-tensioning forces, and the strains in the reinforcement of girders and deck, as well as the strain in the concrete deck and the steel diaphragms.

\subsubsection{External Instrumentation}

The location of LVDTs, inclinometers, and wire potentiometers in the test specimen are shown in Figure 3.9. Three LVDTs were located directly underneath each one of the girders to measure their vertical displacement at midspan (LVDT-1 to LVDT-3). LVDTs were mounted on aluminum frames fixed by weights to the strong floor of the laboratory. Their cores were mechanically connected to the points of measurement by means of 3/16-in. diameter threaded rods. These transformers were Lucas Schaevitz ${ }^{\mathrm{TM}}$ DC-operated Model DC-E 2000 and DC-EC 2000. Figure 3.9 shows the external instrumentation of the test specimen. In Figure 3.9, the concrete deck of the test specimen is not shown to allow for a clearer view of the location of the instrumentation.

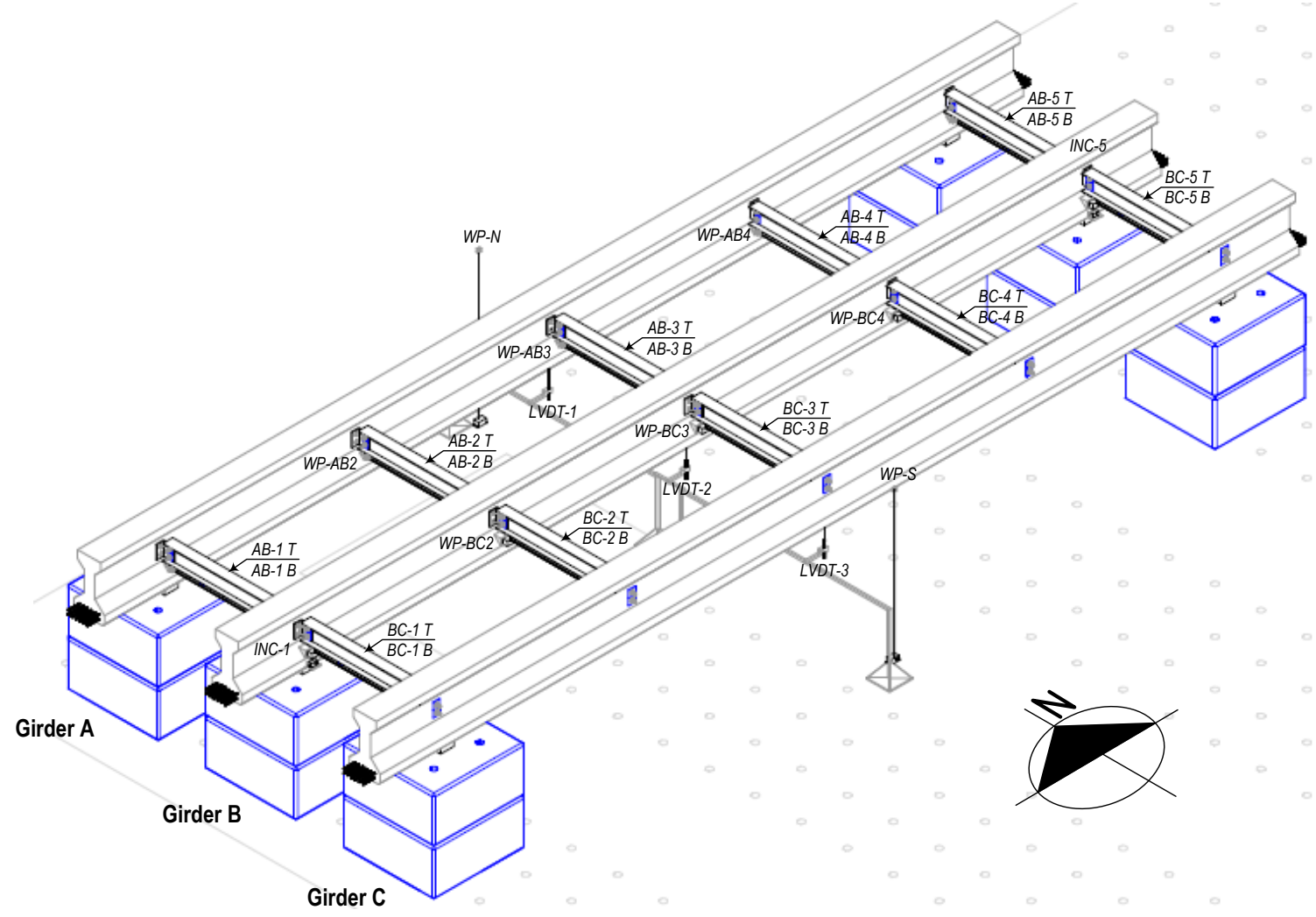

Figure 3.9 External instrumentation of test specimen

An inclinometer was located at each one of the supports of interior Girder B (INC-1 and INC-5). The inclinometers were Model LSOC 14.5 from Lucas Schaevitz ${ }^{\text {TM }}$. They were seated on $2 \times 3-i n$. steel angles that were attached to the side surface of the girders by means of epoxy glue. Six wire potentiometers (WP-AB2, WP-AB3, WP-AB4, WP-BC2, WP-BC3, and WP-BC4) were located transversally in between girders to measure their relative displacement. Their location coincided with the location of the interior steel diaphragms. 
Similarly to the inclinometers, the wire potentiometers were mounted on steel plates that were glued to the girders with epoxy glue. The opposite end of the wire potentiometers had a small hook that connected to the point of measurement by means of a small piece of aluminum. Two additional wire potentiometers (WP-N and WP-S) were located at midspan and were used to determine the deflection at the edge of the deck. Additionally, one strain gage was attached to the top flange ( $A B-x T$ and $B C-x T)$ and another to the bottom flange ( $A B-x B$ and $B C-x B)$ of each steel diaphragm, at their mid-length section. These gages allowed the monitoring of deformations in the diaphragms as the transverse post-tensioning forces were applied to the deck.

\subsubsection{Internal Instrumentation}

The internal instrumentation of the test specimen consisted of electrical resistance strain gages. They were installed on the mild and prestressing reinforcement of the girders, on the reinforcement of the deck, on the post-tensioning bars or embedded directly in the concrete of the deck. The strain gage system was provided by Vishay ${ }^{\circledR}$ Micro-Measurements Group, Inc. (Raleigh, NC) and by TML Tokyo Sokki (Tokyo, Japan). The selection of each type of strain gages depended on the size, type and location of the point of measurement.

Strain gages were installed after grinding the deformations of the bars, dry-abrading the area with 220- and 320-grit silicon carbide paper, wet-abrading with M-Prep Conditioner A and 400-grit silicon carbide paper, cleaning with M-Prep Neutralizer 5-A, and using either M-bond 200 or CN as bonding agent. Each strain gage was connected to the data acquisition system using 26 gage 3-wire cable (Model 326-DFV). Cables were guided along the reinforcement using plastic ties. In the case of strands and post-tensioning bars, no grinding was necessary. Table 3.2 summarizes the types of electrical strain gages used to instrument the test specimen.

Table $3.2 \quad$ Electrical strain gages

\begin{tabular}{ccccc}
\hline Fabricator & Quantity & Type of strain gage & Gage Factor & Location \\
\hline Vishay $^{\circledR}$ & $14 \times 3$ & MM EA-06-125BT-120 & 2.110 & Strands of girders \\
Micro-Measurements & $2 \times 10$ & MM N2A-06-20CBW-120 & 2.100 & Steel diaphragms \\
\hline & $2 \times 3$ & YEFLA-5-11-xLT & 2.110 & Longitudinal reinforcement of girders \\
& $4 \times 3$ & YEFLA-2-11-xLT & 2.160 & Shear reinforcement of girders \\
TML Tokyo Sokki & $3 \times 12$ & YFLA-5 & 2.105 & Longitudinal reinforcement of deck \\
& $3 \times 14$ & YFLA-5 & 2.105 & Transversal reinforcement of deck \\
& $6 \times 2$ & PML-30 & 2.100 & Embedded in deck \\
& 40 & YFLA-5 & 2.100 & Transverse post-tensioning
\end{tabular}

The girders were instrumented with 20 electrical strain gages. Fourteen of those were located on the two layers of prestressing strands, at seven cross sections in the length of the girder. 
Additionally, four stirrups in the midspan region were instrumented at one of their legs. Finally, the two No. 6 bars running along the top flanges had a strain gage installed on each, at the midspan section. All strain gages installed on the mild reinforcement of the girders had pre-attached wires, which were later extended by means of soldering another section of wire. The wires were guided parallel to the reinforcement by means of plastic ties and two outlets with ten strain gages each were formed around the thirds of the girder's length.

The deck was instrumented with 90 electric strain gages. Forty-two of them were installed on the reinforcement parallel to the transverse direction of the deck (TTX-1 to TTX-7, TBx-1 to TBx-7). Thirtysix strain gages were installed on the reinforcement running longitudinally in the deck (LTXX-3, $L B x x-3, L T x x-5, L B x x-5, L T x x-6$, and $L B x x-6)$. The remaining twelve gages were embedded in the concrete at mid-height of the deck's thickness (EAB-1 to EAB-6, and EBC-1 to EBC-6). Steel wire was used to achieve the former. Half of all electrical strain gages installed on the reinforcement were located on the bottom grid. The other half was located on the top mat. Similarly to the prestressed girders, the wires were guided parallel to the reinforcement by means of plastic ties. In the case of the deck, more than a dozen outlet points on the bottom face were necessary to connect the strain gages to the data acquisition system.

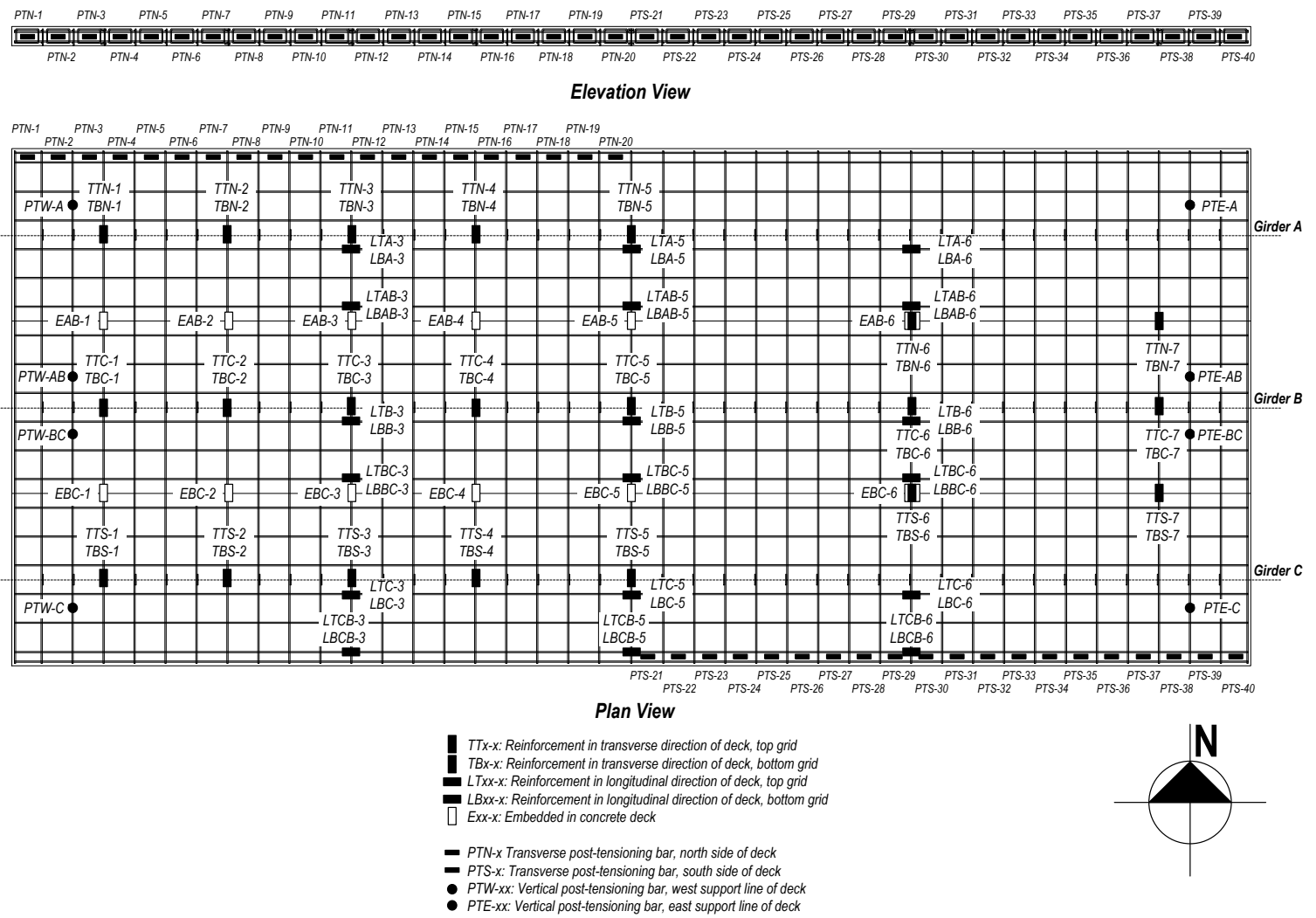

Figure 3.10 Internal instrumentation of test specimen

The wires of strain gages installed on the transverse post-tensioning bars were extracted to the top surface of the deck by means of 1/2-in. diameter black vinyl tubing that connected the PVC 
pipe for the post-tensioning to the surface of the deck. One strain gage was installed on each of the 40 post-tensioning bars. Half of the gages were located in the Northwest quadrant of the test specimen (PTN-1 to PTN-20), and the other half on the Southeast quadrant (PTS-21 to PTS-40). Figure 3.10 shows a general layout of the internal instrumentation of the test specimen. In Figure 3.10, the bursting reinforcement and the transverse post-tensioning bars are not shown to allow for more clarity on the location of the electrical strain gages.

In addition to the transverse post-tensioning, twelve vertical post-tensioning bars were used to restrain the test specimen at support lines. Eight of those bars were instrumented by means of one strain gage on each to monitor the applied force (PTW-xx and PTE-xx). These gages are shown as black circles in Figure 3.10.

\subsection{Test Procedure}

The test specimen was subjected to a series of 32 tests. Each test consisted of applying a given distribution of transverse post-tensioning force, in combination with the presence of a given number of diaphragms, and a given set of boundary conditions (restrain at support lines). Table 3.3 presents the matrix of tests carried out. Tests were identified using four symbols. The first identifier is the number of diaphragm lines. The second identifier is the post-tensioning stress, in $p s i$, at sections of the deck located in between diaphragm regions. The third identifier is the posttensioning stress, in psi, at diaphragm regions, and the fourth identifier is a set of two letters, in which $R R$ represents that both ends of the test specimen were restrained, and NR represents that only the West end of the deck was restrained.

\subsubsection{Test Setup}

The tests were conducted at the Robert L. and Terry L. Bowen Laboratory for Large-Scale Civil Engineering Research at Purdue University. The test configuration required for the design and construction of support concrete blocks. Twelve 4'x4'x2' blocks were designed and built in such a way that they could not only support the demands of the test but also to be able to be used in subsequent testing programs. The blocks were reinforced with No. 4, Gr. 60 reinforcement and had a nominal compressive strength of 6000 psi. Support blocks were cast using a local concrete mixer (Irving Materials, Inc. of Lafayette, Indiana). Two mixing trucks, each with $8.5 \mathrm{yd}^{3}$ of concrete were used.

In order to allow the blocks to be placed on top pf each other, four 1" $x 6$ " coil loop inserts $B-16$ and four 4.5-in. long plastic setting bolts $B-25$ were embedded on the top surface of each block. Additionally, the blocks had four 3-1/4" diameter perforations that allowed them to be anchored down to the strong floor of the laboratory. The perforations were protected by means of PVC pipe. The lifting operation of the support blocks required the use of four 1"x6" coil bolts $B-14$, four 
7"X7"x3/4" flat washers B-11, and four double swivel lifting plates T-26. All lifting accessories and inserts were provided by Dayton Superior of Miamisburg, Ohio.

\section{Table $3.3 \quad$ Test matrix}

\begin{tabular}{|c|c|c|c|}
\hline Test Number & Number of Diaphragms & Post-tensioning stress, psi & Boundary conditions \\
\hline $5 D-400-400-R R$ & \multirow{4}{*}{5} & 400 uniform & \multirow{4}{*}{ Restrained at both ends } \\
\hline $5 D-400-600-R R$ & & $400+600$ at diaphragms & \\
\hline $5 D-800-800-R R$ & & 800 uniform & \\
\hline $5 D-800-1200-R R$ & & $800+1200$ at diaphragms & \\
\hline $5 D-800-1200-N R$ & \multirow{4}{*}{5} & $800+1200$ at diaphragms & \multirow{4}{*}{ Restrained at West eno } \\
\hline $5 D-800-800-N R$ & & 800 uniform & \\
\hline $5 D-400-600-N R$ & & $400+600$ at diaphragms & \\
\hline $5 D-400-400-N R$ & & 400 uniform & \\
\hline $3 D-400-400-R R$ & \multirow{4}{*}{3} & 400 uniform & \multirow{4}{*}{ Restrained at both ends } \\
\hline $3 D-400-600-R R$ & & $400+600$ at diaphragms & \\
\hline $3 D-800-800-R R$ & & 800 uniform & \\
\hline $3 D-800-1200-R R$ & & $800+1200$ at diaphragms & \\
\hline $3 D-800-1200-R$ & \multirow{4}{*}{3} & $800+1200$ at diaphragms & \multirow{4}{*}{ Restrained at West eno } \\
\hline $3 D-800-800-N R$ & & 800 uniform & \\
\hline $3 D-400-600-N R$ & & $400+600$ at diaphragms & \\
\hline $3 D-400-400-N R$ & & 400 uniform & \\
\hline $2 D-400-400-R R$ & \multirow{4}{*}{2} & 400 uniform & \multirow{4}{*}{ Restrained at both ends } \\
\hline $2 D-400-600-R R$ & & $400+600$ at diaphragms & \\
\hline $2 D-800-800-R R$ & & 800 uniform & \\
\hline $2 D-800-1200-R R$ & & $800+1200$ at diaphragms & \\
\hline $2 D-800-1200-N R$ & \multirow{4}{*}{2} & $800+1200$ at diaphragms & \multirow{4}{*}{ Restrained at West enc } \\
\hline $2 D-800-800-N R$ & & 800 uniform & \\
\hline $2 D-400-600-N R$ & & $400+600$ at diaphragms & \\
\hline $2 D-400-400-N R$ & & 400 uniform & \\
\hline$O D-400-400-R R$ & \multirow{4}{*}{0} & 400 uniform & \multirow{4}{*}{ Restrained at both end } \\
\hline $0 D-400-600-R R$ & & $400+600$ at diaphragms & \\
\hline $0 D-800-800-R R$ & & 800 uniform & \\
\hline$O D-800-1200-R R$ & & $800+1200$ at diaphragms & \\
\hline OD-800-1200-NR & \multirow{4}{*}{0} & $800+1200$ at diaphragms & \multirow{4}{*}{ Restrained at West enc } \\
\hline OD-800-800-NR & & 800 uniform & \\
\hline OD-400-600-NR & & $400+600$ at diaphragms & \\
\hline $0 D-400-400-N R$ & & 400 uniform & \\
\hline
\end{tabular}

In addition to the end-restraint imposed by the vertical post-tensioning at support lines, two $1 \mathrm{in}$. long C8" $88^{\prime \prime} \times 1$ " steel angles were located on both sides of each girder. These angles were in 
contact with the bottom flanges of the girders and were post-tensioned against the support blocks by means of 1-1/4-in. diameter Dywidag bars. The function of these angles was to further limit the displacement of the girders in the transverse direction of the bridge.

\subsubsection{Data Acquisition System}

The signals from all the instruments were conditioned and acquired using fourteen Vishay ${ }^{\circledR}$ MicroMeasurements Group scanners (Model 5100), and a personal computer running StrainSmart, a Micro-Measurements proprietary software. Each scanner monitored up to 20 channels. A total of 218 channels were monitored during the tests.

\subsubsection{Test Sequence}

At the beginning of each series of tests with the same number of diaphragms, all channels were zeroed and the vertical post-tensioning at both support lines was done. The restrain at each support line was imposed by means of six post-tensioning bars. These bars went through the deck, the supporting blocks and the strong floor of the laboratory. At each support line, the forces exerted by the vertical post-tensioning bars were transferred to the concrete deck by means of 5"x8"x1-1/2" Dywidag anchor plates, and two C8x11.5, 20-ft long steel shapes connected to each other at their web by means of two rows of eleven Gr. 5 ( $\left.F_{u} \geq 120 \mathrm{ksi}\right), 7 / 8$-in. diameter bolts each.

Each of all six bars at each support line were tensioned to a nominal force of $45000 \mathrm{lb}$. The calculated end-restraint moment at each support line was $270 \mathrm{kip}$-ft. This moment represents half of the maximum dead load moment of the girder-slab composite section in a simply supported condition. Initially, vertical post-tensioning bars corresponding to Girder B were tensioned, starting on the West end support line (see Figure 3.10). After that, the bars around Girder C, located on the South end of the test specimen, were postensioned in the same fashion. Finally the vertical posttensioning bars for Girder A, located on the North end of the test specimen, were postensioned. All post-tensioning was carried out using two Enerpac $\mathrm{RCH}-603$ center-hole rams with a 60 -ton (10000 psi) capacity. The rams were simultaneously powered by an electric SPX PowerTeam PE554 Model C pump. A manifold equipped with a pressure dial was used to distribute identical pressures to both rams.

Once the vertical bars (PTW-xx and PTE-xx) were postensioned, the rams were located on the East and West ends of the deck. Each ram was located on opposite (North and South) edges of the deck -each on a post-tensioning bar- and both bars were tensioned simultaneously. Figure 3.11 shows a side view of the deck with the sequence followed to apply the desired distribution of transverse post-tensioning for the series of the tests with five diaphragms. Tests with fewer diaphragms followed a similar sequence. Load steps are encircled and numbered incrementally. A load step number is associated with two symmetrically opposed locations for transverse posttensioning. The top left numbers correspond to the post-tensioning applied on the North edge of the test specimen (side of Girder A in Figure 3.10), and the numbers shown below are for post- 
tensioning applied along the South edge of the deck (closest to Girder $\mathbf{C}$ in Figure 3.10). For tests where a concentration of transverse post-tensioning force was required, it was applied in bars located within the 4-ft. wide diaphragm regions, shaded in Figure 3.11.

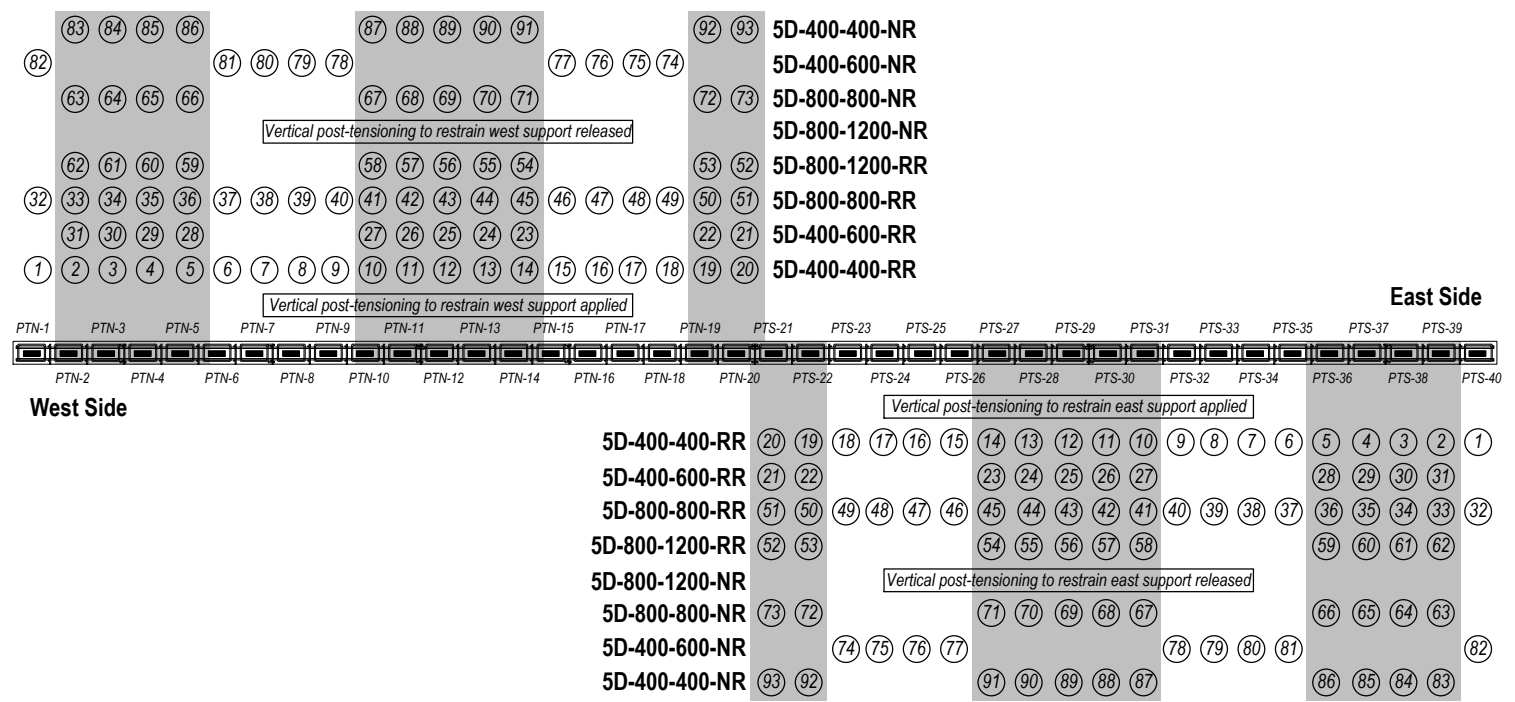

Figure 3.11 


\section{CHAPTER 4 EXPERIMENTAL EVALUATION OF TRANVERSE POST-TENSIONING}

\subsection{Introduction}

This chapter presents the data gathered during the experimental program. An evaluation of the effect of number and location of diaphragms and support restraint on strain distribution due to transverse post-tensioning is carried out. Test results are presented in terms of strain measurements for diaphragms, steel reinforcement in the bridge deck, and in the post-tensioning bars.

In Section 4.3, test results are used to evaluate the design recommendations presented by Ramirez and Smith-Pardo in JTRP Project No. FHWA/IN/JTRP/2002-26 (SPR-2409). Finally, findings from the evaluation are summarized in Section 4.4.

\subsection{Strain Readings}

Thirty-two tests were conducted using the test specimen described in Chapter 3 . During the testing program, the number of diaphragms was decreased from five to none. The end conditions consisted of both ends unrestrained, and one end unrestrainded and the opposite end restrained. Different schemes of transverse post-tensioning were applied to the deck and strains at various points of the structure were measured by means of electrical strain gages. The data gathered through these gages are presented to illustrate the influence of the diaphragms and the influence of support conditions on the distribution of transverse strains in the deck as a result of transverse post-tensioning.

\subsubsection{Strain in Steel Diaphragms}

Five sections were selected for the installation of steel diaphragms on the test specimen. Each diaphragm was instrumented with two strain gages. One gage was installed on the inside face of top flange, and the second was installed on the inside face of the bottom flange. Throughout all tests, readings from both gages in each diaphragm were similar. This indicated a uniaxial state of stress in the diaphragm as a result of the application of post-tensioning force. Figure 4.1 shows the strain readings obtained at the diaphragms between Girder B and Girder C (South side of deck as shown in Figure 3.10) for all tests with two diaphragms and restraint at both end supports (2D- 


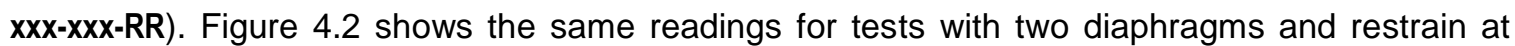
only one support line (2D-xxx-xxx-NR).

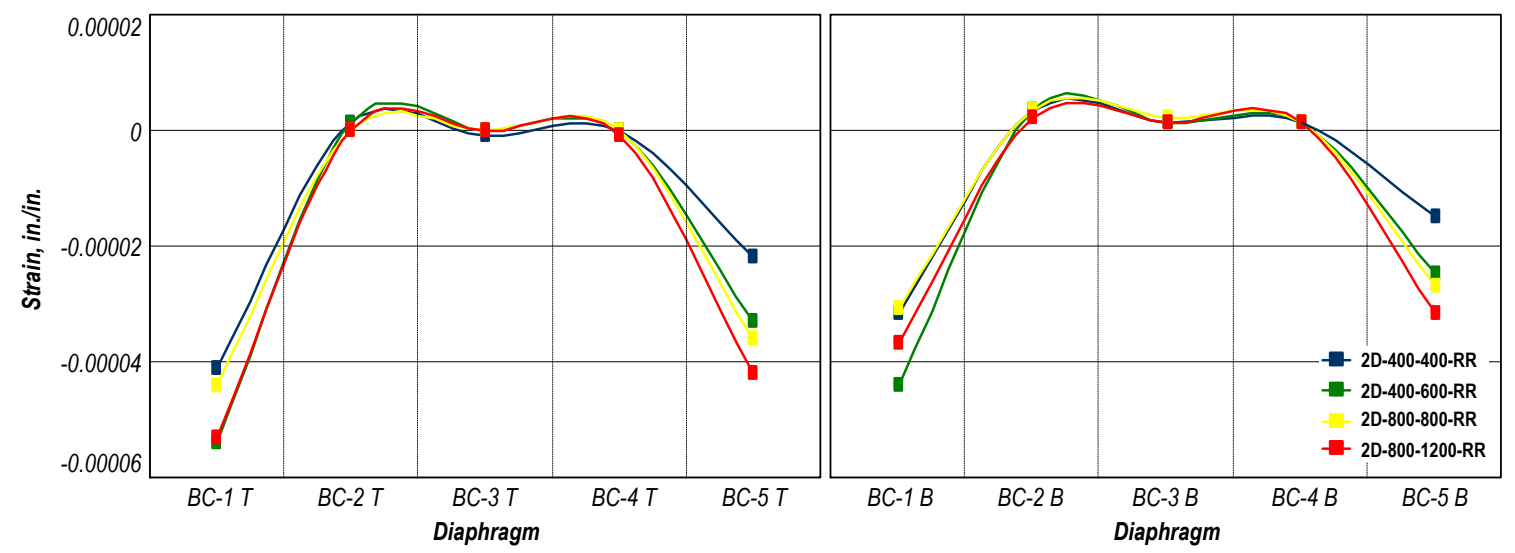

Figure 4.1 Diaphragms strains for tests with two diaphragms and end-restraint at both support lines

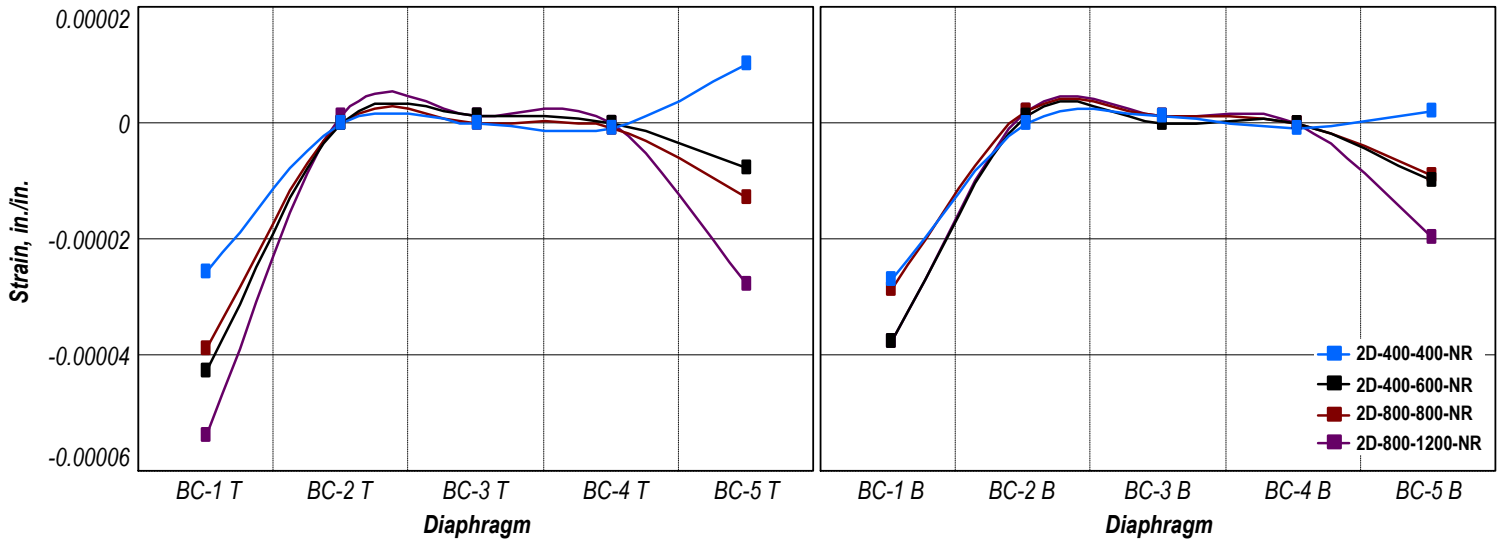

Figure 4.2 Diaphragm strains for tests with two diaphragms and end-restraint at West support line only

Note that strain readings from top and bottom flanges are similar both in magnitude and distribution in all cases (see Figure 4.1). This behavior was also observed in diaphragms located between Girder A and Girder B (North side of deck). In all other tests, with zero, three and five diaphragms, similar behavior was observed. It is plausible to say that the whole section of the steel diaphragms was subjected to compression, even if it was small in magnitude.

Based on the reading from the gages located on the steel diaphragms, it can be concluded that as pointed out by Ramirez and Smith-Pardo (2002), the diaphragms participated during the application of transverse post-tensioning. The maximum strains measured in the diaphragms were under $0.00006 \mathrm{in}$./in. The maximum compression measured in the diaphragms increased as the number of diaphragms installed was decreased. The reduction in the strain of diaphragms between tests with five diaphragms and tests with two diaphragms was around $60 \%$. 


\subsubsection{Strain in Deck Reinforcement}

The reinforcement of the bridge deck was provided in the form of two identical orthogonal mats of No. 4 bars. The reinforcement of both mats was instrumented by means of electrical strain gages. Additional bursting reinforcement, which was not instrumented, was provided in the posttensioning anchorage regions. First, data obtained by the gages attached to the bars running in the transverse direction of the deck are presented. In all cases, the average of three strain gages along the same bar is calculated and plotted. Figure 4.3 shows the transverse strain distribution in the top mat of reinforcement for all tests with end-restraint at both support lines (xx-xxx-xxx-RR). In order to facilitate analysis, all plots are presented using the same scale. In each plot, the first number indicates the number of diaphragms. The second and third identifiers refer to the distribution of concrete stress in psi calculated on the basis of the applied post-tensioning force along the deck edge at the final stage. The second identifier is the level of stress between the diaphragms whereas the third identifier is the concrete stress of the diaphragm region. The last identifier, RR, stands for both ends of the bridge deck restrained.


Figure 4.3

Strains in top mat of transverse reinforcement for tests with end-restraint at both support lines

It must be pointed out that the shape of the strain distribution seen in all plots was similar, regardless of the number of diaphragms installed. Note that even though both supports were restrained, there is a difference between the magnitude of the strains on the West side (left side of the plots) and those on the East side of the deck (right side of the plots). During initial vertical 
post-tensioning of the West end of the deck to induce the restraint, a corner of the deck cracked. This resulted in a significant reduction of the end stiffness of the deck, showed by a concentration of larger strain readings at the West end region. In the bottom grid of reinforcement as shown in Figure 4.4, the measurements indicated that the distribution of strains was symmetric. Thus indicating a reduction in the strain of the West side of the bridge (left side of the plots) with respect to the values measured on the top mat of steel in Figure 4.3. This was indicative that the cracking of the deck was arrested at the level of the top mat reinforcement and did not influence the strains on the bottom mat reinforcement. The application of transverse post-tensioning caused a positive bending of the deck (compression at the top and tension at the bottom) resulting in a strain gradient within the deck. The similarity is maintained throughout all tests, regardless of number and location of steel diaphragms.
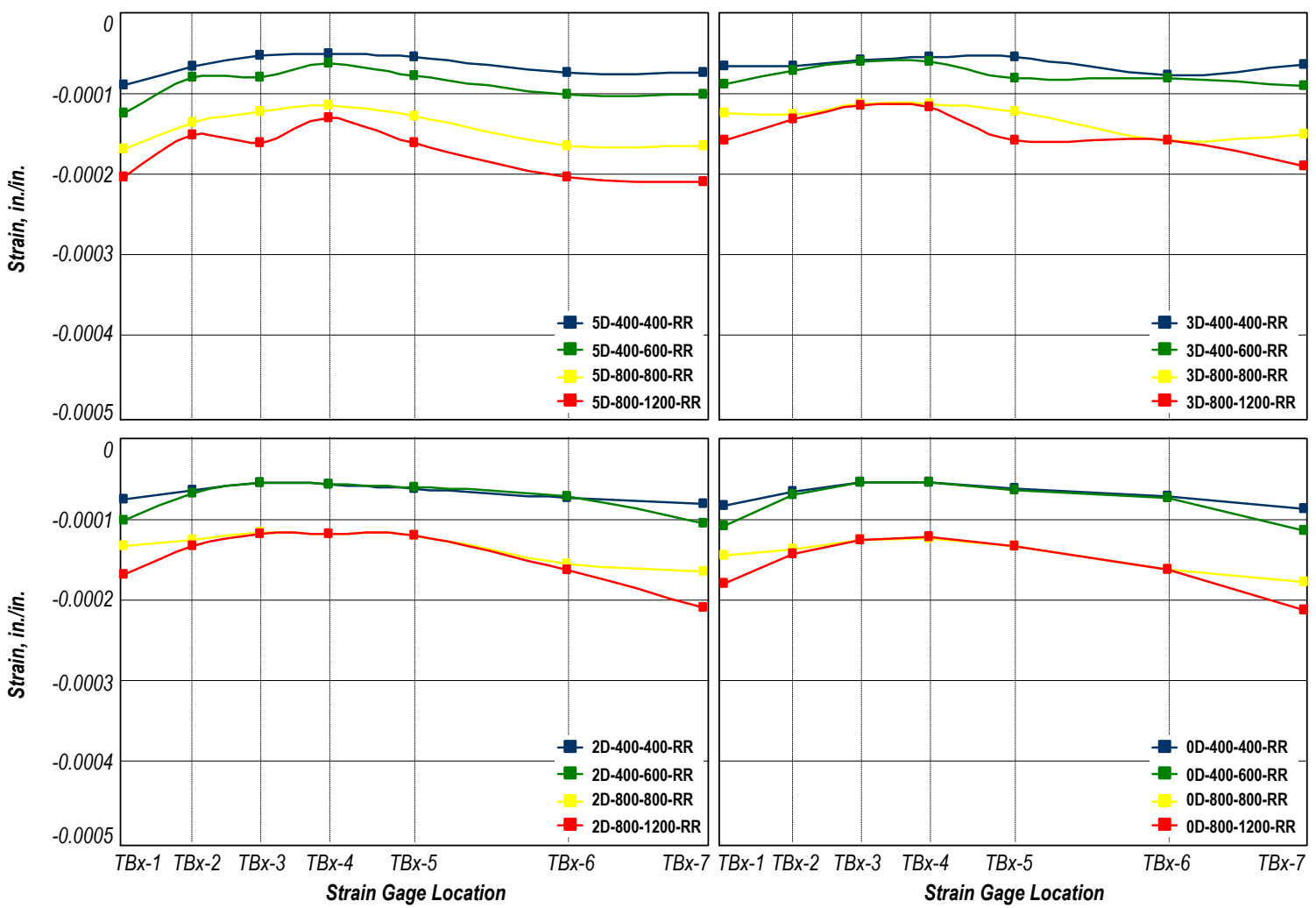

Figure 4.4

Strains in bottom mat of transverse reinforcement for tests with end-restraint at both support lines

Figure 4.5 shows the distribution of strains on the transverse reinforcement of the top mat for all tests with end-restraint only at the West support line (left side of plots). Again, the similarities between plots in Figure 4.3 and Figure 4.5 can be observed. The effect of end-restraint at the East support line (right side of the plots) in the distribution of transverse strains along the bridge deck was very limited. At the West end (left side of the plots), there was a concentration of strain due to a reduction in stiffness from damage to the deck throughout all 32 tests. However, Figure 4.3 and 4.5 show that the distribution of strains remains essentially the same in shape and magnitude after removal of the end restraint. 

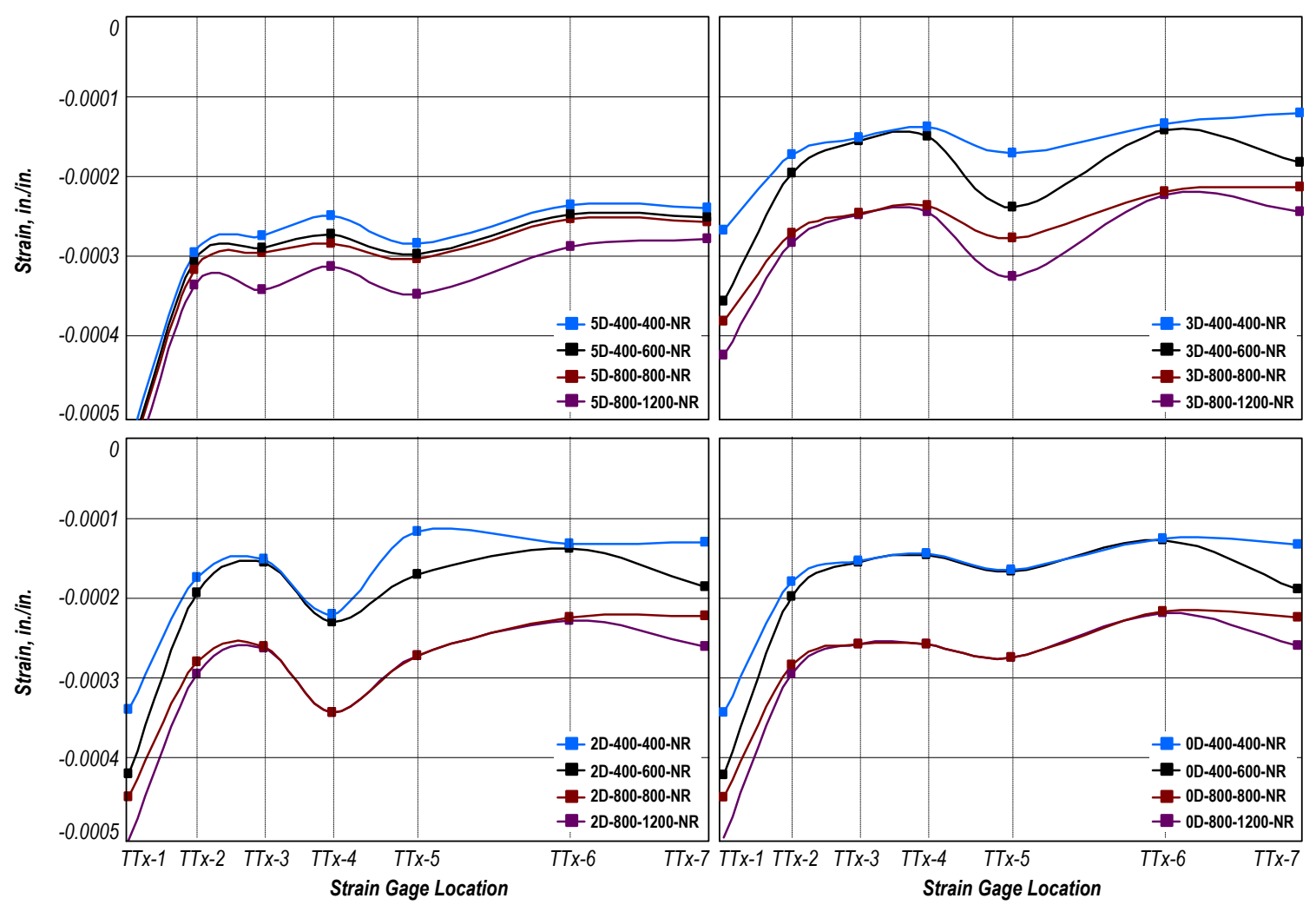

Figure 4.5

Strains in top mat of transverse reinforcement for tests with end-restraint at West support line only

Data obtained from strain gages attached to the reinforcement in the longitudinal direction of the deck showed that the deformations were consisting with estimates based on Poisson's ratio for the concrete in the deck and assumption of uncracked behavior. The magnitude of longitudinal strains did not exceed $0.00012 \mathrm{in}$./in. for any of the 32 tests at any strain gage location. The distribution of longitudinal strains was more or less uniform along the span of the deck. The magnitude of strain increased as the applied post-tensioning force increased.

\subsubsection{Strain in Concrete Deck}

The strain measurements at various locations in the concrete deck were obtained by means of twelve embedded strain gages located at mid-height of the thickness of the deck. The distribution of concrete strains along the span of the deck was shown to be uniform regardless of the level of transverse post-tensioning force applied. The number and location of diaphragms, as well as the end-restraint condition of the test specimen had also little impact on the distribution of strain.

\subsection{Concrete Transverse Stresses}

Transverse stresses in the concrete were computed on the basis of elastic behavior and using the compressive strength of concrete determined from the test cylinders. They were calculated 
using the strain readings on the transverse longitudinal bars times the modulus of elasticity of the concrete. These estimated stresses were then compared with the distributions shown in Figure 4.6.
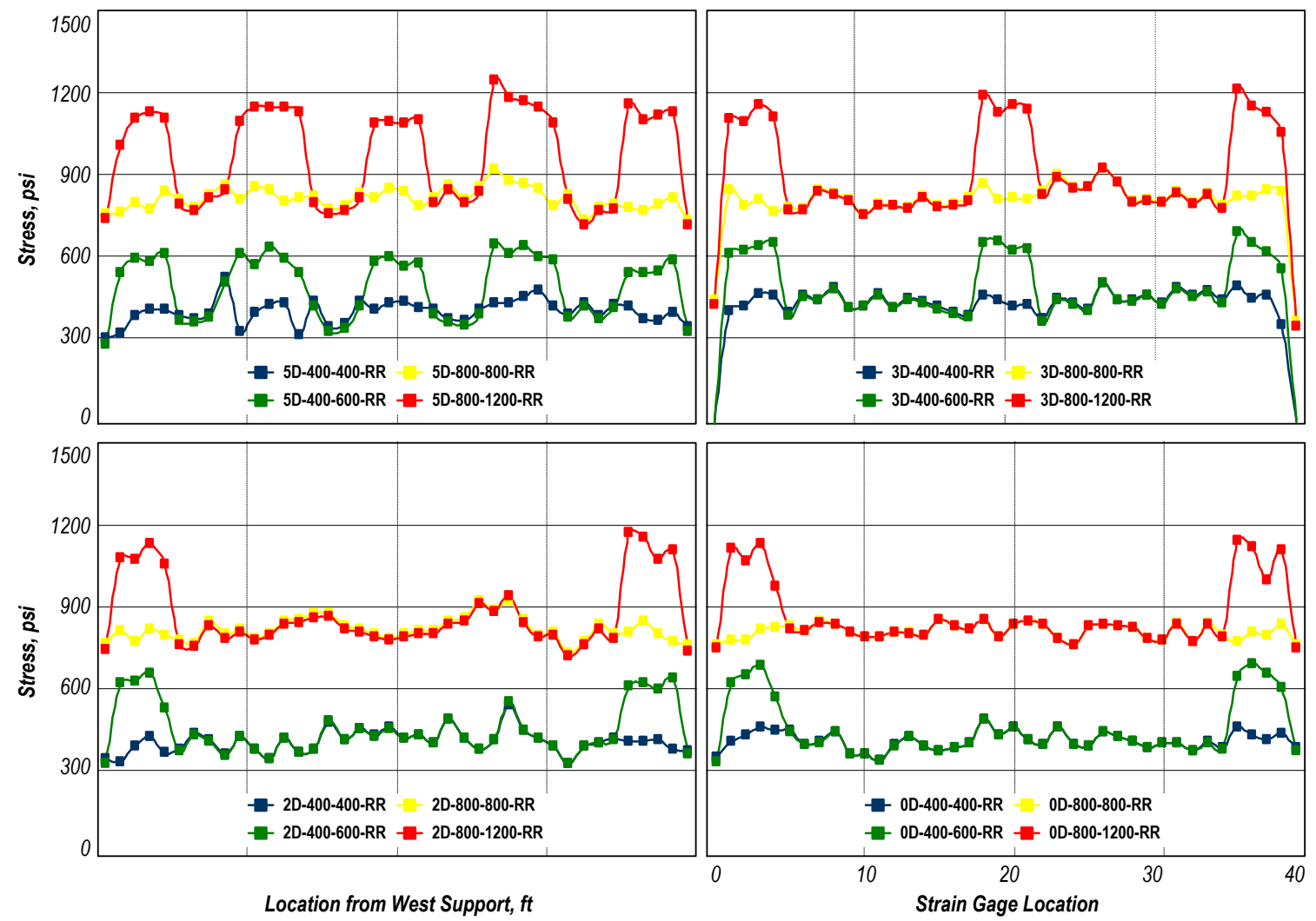

Figure 4.6 Concrete deck stress distribution for tests with end-restraint at both support lines

Figure 4.6 shows the distribution of concrete stresses due to applied post-tensioning force for all tests with end-restraint at both support lines (xx-xxx-xxx-RR). These were obtained by multiplying the strain reading in the transverse post-tensioning bars times the modulus of elasticity of steel $\left(E_{s}=29700 \mathrm{ks}\right)$. The steel stress was then converted to force by multiplying it by the area of the post-tensioning bar. The resulting concrete stress was obtained dividing the post-tensioning force by the tributary concrete area (12 in. $\left.x 8 \mathrm{in} .=96 \mathrm{in}^{2}\right)$. There was close agreement between both values for all 32 tests at all sections except for those on the West side of the bridge.

\subsection{Key Findings}

The following findings are the result of the experimental observations:

- Based on the readings from the gages located on the steel diaphragms, it can be concluded, that as pointed out by Ramirez and Smith-Pardo (2002), the diaphragms participated during the application of transverse post-tensioning. The measurements 
indicated that when present regardless of the number and location, the diaphragms were subjected to axial compression, even though small.

- Based on the measurement of strains on both mats of transverse reinforcement for all tests conducted (Figures 4.3 and 4.5), regardless of number and location of steel diaphragms, it can be stated that they had very limited impact on the transverse strain distribution.

- In the bottom grid of reinforcement as shown in Figure 4.4, the measurements indicated a symmetric distribution of strains. Thus, a reduction in the strain on the West side of the bridge (left side of the plots) with respect to the values measured on top mat of steel in Figure 4.3 was observed. This indicates that the application of post-tensioning also caused a positive bending of the deck (compression at the top and tension at the bottom) resulting in a strain gradient within the deck that then superimposed on the strains resulting from transverse post-tensioning. The same observation was true for all tests, regardless of number and location of diaphragms.

- The similarities between plots in Figure 4.3 and Figure 4.5 showed that the effect of end-restraint at the East support line (right side of the plots) on the distribution of transverse strains along the bridge deck was very limited. At the West end (left side of the plots), there was a concentration of strain throughout all 32 tests. This observation could be explained by a reduction in stiffness from damage to the deck. However, Figures 4.3 and 4.5 showed that the distribution of strains remained essentially the same in shape and magnitude after removal of the end restraint.

- Data obtained from strain gages attached to the reinforcement in the longitudinal direction of the deck showed that the deformations were consisting with estimates based on Poisson's ratio for the concrete in the deck and assumption of uncracked behavior. The distribution of longitudinal strains was more or less uniform along the span of the deck. The magnitude of strain increased as the applied post-tensioning force increased.

- The calculated stresses in the concrete using strain measurements on the transverse deck reinforcement using linear elastic behavior and actual measured concrete properties showed agreement with the values calculated from the strain measurement on the transverse post-tensioning bars. This observation is limited to the range of post-tensioning force used in these tests. However, the agreement was not observed for the West end of the bridge kept restrained throughout all 32 tests, and which was cracked during the initial vertical post-tensioning operation. 


\section{CHAPTER 5 SUMMARY, CONCLUSIONS AND IMPLEMENTATION}

\subsection{Summary}

Damage due to corrosion of reinforcement or freeze-thaw cycles to concrete decks has been identified as the primary bridge maintenance problem in Indiana. In both instances of damage causation are associated or made worst by the extent of cracking on the concrete bridge deck. Poston et al. (1987) observed that the use of transverse post-tensioning controlled the extent of cracking and significantly restricted the penetration of water, chloride and oxygen, thus extending the life of the bridge.

In the FHWA/IN/JTRP/2002-26 (SPR-2409) Report, design expressions for the use of transverse post-tensioning were developed based on extensive analytical studies (Ramirez and SmithPardo, 2002). Experimental results from previous research programs -particularly that of Poston et al. (1987)- were used to validate the design specifications. In the Ramirez and Smith-Pardo (2002) Report, emphasis was placed on the development of design guidelines for the application of transverse post-tensioning force along the deck edge required to meet desirable levels of compression stresses on its top surface. Based on the analytical work, it was recommended that the required distribution of transverse post-tensioning should be such that different application levels of prestressing are required in regions containing interior and exterior (or outermost) diaphragms. It was also concluded that the magnitude of such transverse forces primarily is a function of the girder's boundary conditions, the axial stiffness of the diaphragms, the skew angle of the deck, and the position of the diaphragms/stiffeners with respect to the edge of the deck. The parametric study also pointed out that the use of transverse post-tensioning in integral bent spans could have limited effectiveness in the region adjacent to integral supports.

The design specifications developed in the Ramirez and Smith-Pardo (2002) report were preliminary and not proposed for immediate use until:

(1) the key modeling assumptions in the parametric study were tested in the laboratory, and

(2) a subsequent field phase consisting of the monitoring of a pilot structure.

Chapter 2 of the report of the present Study SPR 2944 provides a brief literature review of previous relevant experimental works and the analytical work conducted by Ramirez and SmithPardo (2002). The research program described in Chapter 3 addresses the first recommendation of Ramirez and Smith-Pardo (2002) above. The experimental program documented was put 
together and conducted to evaluate in the laboratory the key modeling assumptions of the analytical study conducted by Ramirez and Smith-Pardo (2002), and their recommendations on needed distribution of transverse post-tensioning in concrete bridge decks. A rectangular concrete bridge deck supported on precast prestressed concrete girders was built and 32 tests were conducted with it. Information on the materials used in the construction of the test specimen, design, geometric properties, construction sequence, instrumentation, and testing protocols is given in Chapter 3. The key parameters of the study were the effect of girder boundary conditions and position of the diaphragms. The number of steel diaphragms was varied from five to none, and the applied transverse stress from 400 to 1,200 psi. Also, the restraint at one of the support lines was varied to evaluate the effect of end-restraint on the distribution of transverse posttensioning. Due to laboratory limitations, the effect of the angle of skew of the deck was not evaluated.

In Chapter 4, the experimental results were summarized together with the results of the analysis of the data. The analysis of the results of the experimental program, focused on the validation of the findings of Ramirez and Smith-Pardo (2002). The study summary, conclusions and recommendations for implementation are given in Chapter 5 together with a brief summary of suggested future work.

\subsection{Conclusions}

The experimental results showed that the steel diaphragms participated during the application of transverse post-tensioning to the deck. The measurements indicated that when present regardless of the number and location, the diaphragms were subjected to axial compression, even though this was small in magnitude.

The similarities between plots in Figure 4.3 and Figure 4.5 showed that the effect of end-restraint at the East support line (right side of the plots) on the distribution of transverse strains along the bridge deck was very limited. At the West end (left side of the plots), there was a concentration of strain throughout all 32 tests. This observation could be explained by a reduction in stiffness from damage to the deck. However, Figures 4.3 and 4.5 showed that the distribution of strains remained essentially the same in shape and magnitude after removal of the end restraint.

The calculated stresses in the concrete using strain measurements on the transverse deck reinforcement using linear elastic behavior and actual measured concrete properties showed agreement with the values calculated from the strain measurement on the transverse posttensioning bars. This observation is limited to the range of post-tensioning force used in these tests. However, this agreement was not observed for the West end of the bridge that was kept restrained throughout all 32 tests, and which was cracked during the initial vertical posttensioning operation. 
Based on the key findings from the experimental program, the following conclusions can be made with regard to the proposed design recommendations by Ramirez and Smith-Pardo (2002):

- Even though the assumptions of the participation of diaphragms was confirmed by the experimental values, it did not resulted in variation of concrete stresses in the magnitude envisioned in the 2002 study.

- The effect of end restraint could not be established with sufficient confidence to justify a reduction in the concrete deck stresses resulting from the transverse posttensioning of the same.

- Away from the restrained end of the bridge deck (West side), in the range of posttensioning estimated to maintain uncracked condition under service loads, the use of uniform transverse post-tensioning is deemed appropriate.

\subsection{Proposed Implementation}

Following the evaluation in the laboratory of the Ramirez and Pardo-Smith (2002) design recommendations for transverse post-tensioning, the proposed next step in the implementation process is to identify a bridge structure in Indiana where uniform transverse post-tensioning of the bridge deck is employed. It is also recommended that the performance of the structure be monitored on a long-term basis. The monitoring plan envisioned would consist of an initial phase during construction and first year of existence, followed by regular monitoring as part of the regular course of Indiana bridge inspection practice.

It is suggested that a bridge with integral end abutments be considered as the field structure and that the deck consists of a cast in-place slab supported on pretensioned bridge girders acting composite with the deck. If diaphragms are employed, it is recommended the use of steel diaphragms. The envisioned instrumentation would consist of strain gages to measure long-term level of prestress force and concrete deck stresses. The gages would be mounted on the transverse deck bars and post-tensioning rods. Embedded sensors in the concrete deck to monitor temperature and humidity, strain gages on the diaphragms and monitoring of deck concrete properties are also recommended. It is proposed that the regular inspection during the initial phase includes cracking and chloride level determinations. It is envisioned that the longterm inspection would include determination of chloride levels and monitoring of transverse posttension force levels.

\section{$5.4 \quad$ Future Work}

Examination of the practice of transversely post-tensioned concrete bridge decks on steel girders is recommended as a possible follow up work. The effect of concrete diaphragms was not investigated in the study reported herein. 


\section{REFERENCES}

ACl Committee 318 (2008), Building Code Requirements for Structural Concrete (ACl 318-08) and Commentary, American Concrete Institute, Farmington Hills, Ml, 465 pp.

Almustafa, R.A. (1983), The Analysis of Transverse Prestressing Effects, Ph.D. Thesis, University of Texas at Austin, $274 \mathrm{pp}$.

ASTM A 370-05, Standard Test Methods and Definitions for Mechanical Testing of Steel Products, American Society for Testing and Materials, West Conshohocken, PA, 2005, 47 pp.

ASTM A 615-05, Standard Specification for Deformed and Plain Carbon-Steel Bars for Concrete Reinforcement, American Society for Testing and Materials, West Conshohocken, PA, 2005, 6 pp.

ASTM C 39-04, Standard Test Method for Compressive Strength of Cylindrical Concrete Specimens, American Society for Testing and Materials, West Conshohocken, PA, 2004, 7 pp.

ASTM C 143-05, Standard Test Method for Slump of Hydraulic-Cement Concrete, American Society for Testing and Materials, West Conshohocken, PA, 2005, 4 pp.

ASTM C 192-05, Standard Practice for Making and Curing Concrete Test Specimens in the Laboratory, American Society for Testing and Materials, West Conshohocken, PA, 2005, 8 pp.

ASTM C 231-04, Standard Test Method for Air Content of Freshly Mixed Concrete by the Pressure Method, American Society for Testing and Materials, West Conshohocken, PA, 2004, 9 pp.

ASTM C 1231-00, Standard Practice for Use of Unbonded Caps in Determination of Compressive Strength of Hardened Concrete Cylinders, American Society for Testing and Materials, West Conshohocken, PA, 2000, 4 pp.

Blaha, B. (1980), Idea Packed Segmental Bridge Connects to Florida Keys, Concrete Products.

Bishara, A.G., and Elmir, W.E (1990), Interaction Between Cross Frames and Girders, Journal of Structural Engineering, ASCE, Vol. 116, No.5, pp. 1319-1333.

Bishara, A.G., Liu, M.C., and El-Ali, N.D. (1993), Wheel Load Distribution on Simply Supported Skew IBeam Composite Bridges, Journal of Structural Engineering, ASCE, Vol. 110, No.2, pp. 339-419.

Boecker-Ralls, M.L. (1984), Stress Distribution in a Transversally Prestressed Slab-Girder Bridge Deck, Master's Thesis, University of Texas at Austin, $147 \mathrm{pp}$.

Chan, T.H., and Chan, J.H. (1999), The Use of Eccentric Beam Elements in the Analysis of Slab-onGirder Bridges, Structural Engineering ands Mechanics Journal, Vol. 8, No. 1, pp. 85-102.

Mabsout, M., Tarhini, K., Frederick, G., and Kesserwan, A. (1999), Effect of Multi-lanes on Wheel Load Distribution in Steel Girder Bridges, Journal of Bridge Engineering, ASCE, Vol. 4, No. 2, pp. 99-106.

Mabsout, M., Tarhini, K., Frederick, G., and Tayar, C. (1997), Finite-element Analysis of Steel Girder Highway Bridges, Journal of Bridge Engineering, ASCE, Vol. 2, No. 3, pp. 83--87.

Mora, R.A. (1983), Design and Construction of a Direct Model for the Study of Transverse Prestressing of Bridge Decks, Master's Thesis, University of Texas at Austin, $63 \mathrm{pp}$.

Phipps, A.R. (1985), The Design of Transversally Prestressed Bridge Decks, Master's Thesis (1), University of Texas at Austin, $146 \mathrm{pp}$.

Phipps, A.R.(1985), The Design of Transversally Prestressed Bridge Decks, Master's Thesis (2), University of Texas at Austin, $365 \mathrm{pp}$.

Postensioning Institute (1997), Post-Tensioning Manual, $5^{\text {th }}$ Edition, Phoenix, AZ, $406 \mathrm{pp}$.

Poston, R.W. (1984), Improving Durability of Bridge Decks by Transverse Prestressing, Ph.D. Thesis, University of Texas at Austin, $637 \mathrm{pp}$. 
Poston, R.W., Breen, J.E., and Carrasquillo, R.L. (1989), Design of Transversely Prestressed Concrete Girders, PCl Special Report, pp. 68-101.

Poston, R.W., Carrasquillo, R.L., and Breen, J.E. (1987), Durability of Post-tensioned Bridge Decks, ACl Materials Journal, 84 (4), pp. 315-326.

Poston, R.W., Phipps, A.R., Breen, J.E., and Carrasquillo, R.L. (1985), Design Procedures for Prestressed Concrete Bridge Decks, Research Report 316-3F, Project 3-8316, Center for Transportation Research, Bureau of Engineering Research, University of Texas at Austin, $175 \mathrm{pp}$.

Ralls, M.L. (1984), Stress Distribution in a Transversely Prestressed Slab-Girder Bridge Deck, Master's Thesis, University of Texas at Austin, $147 \mathrm{pp}$.

Randall, R.W, Phipps, A.R., Almustafa, R.A., Breen, J.E., and Carrasquillo, R.L. (1988), Effects of Transverse Prestressing in Bridge Decks, Journal of Structural Engineering, ASCE, Vol. 114, No. 4, pp. 743-764.

Ramirez, J.A. and Smith-Pardo, J.P. (2002), An Investigation on Transversely Prestressed Concrete Bridge Decks, Report FHWA/IN/JTRP/2002-26 (SPR-2409), 168 pp.

Tedesko A. (1976), Bridge decks: transverse post-tensioning and other successful experiences, $\mathrm{ACl}$ Journal, 73 (12), pp. 665-670. 